\title{
Glucosinolates With Their Hydrolysis Products from Two Cruciferous Plants with Study of Antidiabetic Activity Based on Molecular Docking
}

\author{
Khaled Abdelshafeek \\ Al-Bha unveristy \\ Walid E. Abdallah \\ NRC Egypt
}

Ahmed elhenawy ( $\square$ elhenawy_sci@hotmail.com )

Al-Azhar University Faculty of Science https://orcid.org/0000-0003-2893-0376

\author{
Abeer Alothami \\ Taif University \\ Lila Alharby \\ ubd Alaziz unveristy \\ Abd ulaziz Alomari \\ Al Bhaa unveristy
}

Research article

Keywords: Crucifereae, Carrichtera annua, Farsetia aegyptia, GC/MS, DOCKING, glucosinolates and isothiocyanates

Posted Date: November 12th, 2020

DOI: https://doi.org/10.21203/rs.3.rs-103757/v1

License: (9) This work is licensed under a Creative Commons Attribution 4.0 International License. Read Full License 


\section{Abstract}

The glucosinolates (Gls.) are natural bioactive compounds which lead to the formation of different metabolites called isothiocyanates(ITC) having various therapeutic effects. So, this study aim to isolate the glucosinolates of both Carrichtera annua L.(DC) (CA) and Farsetia aegyptia Turra (FA) belonging to Crucifereae family. The total Gls. were isolated from the aqueous methanolic extract of both plants and further purified on acidic aluminum oxide column. Some of the obtained Gls. was identified as it is using different spectroscopic measurements (UV, NMR and MS) and the rest were hydrolyzed using myrosinase enzyme to the corresponding isothiocyanates (ITC) which were identified by GC/MS. only one glucosinolate was identified in CA as: 4-methylthio-3-butenyl Gls (MTBG). through chromatographic and spectroscopic measurements in addition to 6-methyl sulfonylhexyl isothiocyanates(ITC), while 6-methyl sulfonyl-6-hydroxy hexyl ITC, 4-pentenyl ITC, 3-Methylthio propyl ITC, 5hydroxy pentyl ITC and 4-methylsulphinyl butyl ITC from FA. The docking study targeted a a-glucosidase and amylase, to examine a mode of action of the 4-methylthio-3-butenylglucosinolate. Molecular docking was performed to identify potency of Gls. against hyperglycemia. The data obtained revealed that the Gls. has high binding activity Via a-glucosidase and amylase. Furthermore, further Drug studies as likeness and ADME/T were performed, which proposed that their ligands may be have a good pharmacokinetic character, with no carcinogenesis effect.

\section{Introduction}

Many plants of the Cruciferae (formerly Brassicaceae) contain glucosinolates which are precursors of strongly odorous pungent isothiocyanates formed by the action of enzyme myrosinase on the glucosinolate substrate when the plant tissues are ruptured[1]. The family Cruciferae consider as one of the largest angiosperm families. It includes many of economically important plants as vegetable salad plants and crop species. The plants of this family have many biological activities like anticancer, antibacterial, antifungal, antirheumatic and antidiabetic[2]. Carrichtera and Farsetia are two genera belonging to Crucifereae family represented in Egypt by only one species known as $C$. annua L.(DC) for Carrichtera genus growing in Sinai peninsula specially at Elarish region, while Farsetia genus is represented by three species in which F. aegyptia Turra. is more popular and growing at many localities in Egypt [3]. The two plants are known to be used by the native Bedouins as antidiabetic and antispasmodic. Moreover, F. aegyptia is used for the relieve of rheumatic pains and taken as a cooling medicine after pounding. F. aegyptia are prepared as a decoction for toothache, gingivitis and sore eyes. Also, a decoction of the plant mixed with alum is used as a mouth rinse and for mouth disinfection[2-4]. The chemical structure of glucosinolates (Gls.) was found to contain a thioglucosidic bond to the carbon of a sulphonated oxime which attached to a side chain (R group) which may be aliphatic (e.g. alkyl, alkenyl, hydroxy alkenyl, thioalkyl) aliphatic aromatic (eg. Benzyl, substituted benzyl), or heterocyclic (e.g.indolyl,)as shown in chart 1[3]. Gls. and their hydrolysis products (Isothiocyanates,ITC) have different biological activities, like anticancer, antibacterial, antifungal, antioxidative, and allelopathic properties.

Isothiocyanates such as sulforaphane, iberin, phenylethyl and propenyl, derived from glucoraphanin, glucoiberin, gluconasturtiin and sinigrin,respectively, have been found to induce phase -2 enzymes promoting antiproliferative activity[5-8]. The glucosinolates and their hydrolysis products in suspesion culture following elicitation of F. aegyptia were found to contain glucotropaeolin(bezyl Gls.) and gucocheirolin(3-methylsulfonylpropyl-Gls), isobutyl Gls. and gluconasturtiin in addition to identification of 22 hydrolysis products[9, 10]. The total glucosinolates of both $C$. annua and $F$. aegyptia exhibited strong antifeedant effect against the 4th instar larvae of Egyptian cotton leaf worm, S. littoralis and proved to be highly potent, with the ovipositional repellent effect reaching $100 \%$ [4]. In addition, diabetes mellitus is a chronic endocrine disorder that affects the metabolism of carbohydrates, proteins, fat, electrolytes and water. It includes a group of metabolic diseases characterized by hyperglycemia, in which blood sugar levels are elevated either because the pancreas do not produce enough insulin or cells do not respond to the produced insulin [11].Therefore a therapeutic approach to treat diabetes is to decrease postprandial hyperglycemia [12]. This can be achieved by the inhibition of carbohydrate hydrolyzing enzymes like alpha amylase and alpha glucosidase. Alpha glucosidase and amylase are the important enzymes involved in the digestion of carbohydrates. Alpha Amylase is involved in the breakdown of long chain carbohydrates and alpha glucosidase breaks down starch and disaccharides to glucose. They serve as the major digestive enzymes and help in intestinal absorption. Alpha glucosidase and amylase inhibitors are the potential targets in the development of lead compounds for the treatment of diabetes[11, 12]. Consciously, Docking and DFT simulations are powerful computational tools that have been proven to be smarter, inexpensive and efficient approaches for understanding fundamental characters of Biomolecules[13]. DFT calculations gain the important topographic and molecular characters about molecular system as; optimization geometry, chargetransformation, global and local reactivities nature for the molecule and specific regions, respectively,....etc[14-16]. The molecular docking explores the possible binding mode of the compound via its target protein. Its process involves the prediction of ligand-receptor orientation, that useful to guide us for improve compound features[17]. That leads to investigate in the future the efficiency of biomolecule which effective in drug designing. The present study aims to isolation and identification of glucosinolates and their hydrolysis products of both $C$. annua and $F$. aegyptia growing in Egypt. Also, we combined the DFT, ADMET and the molecular docking analysis which will be useful in the future In-vivo studies as antidiabetic agent of this molecule.

\section{Results And Discussion}




\subsection{Isolation and identification:}

The total Gls of both plants were isolated and further purified to afford two compounds (CA1 and CA2) from CA and five compounds (FA1FA5)from FA which were identified as follow:

CA1- 4-methylthio-3-butenyl G/s: The compound was isolated as an off-white amorphous powder and appear as a brown spot $\left(\mathrm{R}_{\mathrm{b}}=0.52\right)$ after spraying with modified $\mathrm{AgNO}_{3}$ reagent. The UV absorption spectrum of the compound in methanol showed $\lambda_{\text {max }}$.at $208 \mathrm{~nm}$ which shifted to $217 \mathrm{~nm}$ by addition of $\mathrm{NaOH}$. When sliver nitrate solution (1\%) was added a new maximum appeared at $260 \mathrm{~nm}$ in addition to the first peak at $215 \mathrm{~nm}$ with increase in intensity, indicates the glucosinolate nature of the compound [18].

The ${ }^{1} \mathrm{H}-\mathrm{NMR}$ spectrum (DMSO) showed signals at $\delta$ in ppm 2.13(3H, s, $\left.\mathrm{CH}_{3}-\mathrm{S}\right), 2.35(2 \mathrm{H}, \mathrm{t}, \mathrm{H}-1), 2.7(2 \mathrm{H}, \mathrm{q}, \mathrm{H}-2), 4.75(1 \mathrm{H}, \mathrm{d}, \mathrm{J}=8.2 \mathrm{~Hz}$ with a small $\mathrm{t}, \mathrm{H}-3), 5.8(1 \mathrm{H}, \mathrm{d}, \mathrm{J}=8.2 \mathrm{~Hz}, \mathrm{H}-4)$, the anomeric proton of glucose displayed as a doublet at $5.1 \mathrm{ppm}$. The complex group of signals between 3.1 and 3.85are characteristic for the rest proton of the glucose moiety. The ${ }^{13} \mathrm{C}-\mathrm{NMR}$ spectrum gave the anomeric carbon of the glucose unit at 82.16 , the two carbon atoms (C-3 and C-4) of the double bond appeared at 137 and $115.6 \mathrm{ppm}$ respectively and the central carbon of the Gls was assigned at $156.21 \mathrm{ppm}$. The other data were summarized in table-1. These findings were coincided with that reported by Manuela et al in 1992 [11]. The GC/MS of the isolated aglucone of this compound after the enzymatic hydrolysis gave only one peak for the corresponding isothiocyanate which identified through it's fragmentation pattern as follow: the mass spectrum displayed a mass to charge ratio ( $m / z)$ of 159 due to the molecular ion peak $\mathrm{M}^{+}$which correspond to the molecular formula $\mathrm{C}_{5} \mathrm{H}_{7} \mathrm{~S}_{2} \mathrm{~N}$, in addition to the fragment ion peaks at $m / z 144\left(\mathrm{M}^{+}\right.$$\left.\mathrm{CH}_{3}\right), 101\left(\mathrm{M}^{+}-\mathrm{NCS}\right)$ and $73\left(\mathrm{M}^{+}-\mathrm{CH}_{2} \mathrm{NCS}\right)$. By comparing these data with the reported data, it was found that, the fragmentation pattern is the same that reported for 4-methylthio-3-butenyl ITC, so, the chromatographic and spectroscopic measurements could be identified compound CA1 as 4-methylthio-3-butenyl glucosinolate.

Table $1:{ }^{13} \mathrm{C}-\mathrm{nm}$ data of compound CA1:

\begin{tabular}{|ll|}
\hline Carbon no. & Sin ppm \\
\hline C1 & 31.75 \\
\hline C2 & 30.44 \\
\hline C3 & 137.01 \\
\hline C4 & 115.6 \\
\hline S-C5 & 24.35 \\
\hline C=N & 156.21 \\
\hline C1' & 82.16 \\
\hline C2 $^{\prime}$ & 72.94 \\
\hline C3' $^{\prime}$ & 78.15 \\
\hline C4' $^{\prime}$ & 69.79 \\
\hline C5 $^{\prime}$ & 81.15 \\
\hline C6 $^{\prime}$ & 60.93 \\
\hline
\end{tabular}

CA2- 6-methylsulfonylhexyl Gls: this compound was isolated in a small amount about 3 mg as a white yellowish powder which is not enough for $\mathrm{nmr}$ measurements. so, it subjected to enzymatic hydrolysis and identification the resultant ITC as follow: the mass spectrum exhibited $\mathrm{M}^{+}$ at $m / z$ of $221(20.5 \%)$ which fit to the molecular formula $\mathrm{C}_{8} \mathrm{H}_{15} \mathrm{O}_{2} \mathrm{NS}_{2}$. The other fragments at $m / z=220\left(\mathrm{M}^{+}-1,23 \%\right), 205\left(\mathrm{M}^{+}-\mathrm{CH}_{3}, 100 \%\right)$, $163\left(\mathrm{M}^{+}-\mathrm{NCS}, 40 \%\right)$ and $142\left(\mathrm{M}^{+}-\mathrm{CH}_{3} \mathrm{SO}_{2}, 35 \%\right)$. This fragmentation pattern confirm the identification of the aglucone as 6-methylsulfonylhexyl ITC $\left[\mathrm{CH}_{3} \mathrm{SO}_{2}-\mathrm{CH}_{2}-\left(\mathrm{CH}_{2}\right)_{4}-\mathrm{CH}_{2}-\mathrm{NCS}\right]$ and accordingly the compound was identified as: 6-methylsulfonylhexyl G/s. This is the first report about the isolation of these compounds from $C$. annua growing in Egypt.

The GC/MS data of the Gls. Hydrolysis products from FA was matched with the previously published data [18, 19], it was found that, the Gls, hydrolysis products included only isothiocyanates which were identified in an increasing of their retention manner as follow:

FA1 - 6-methylsulfonyl6-hydroxy-hexyl ITC. $\mathrm{R}_{\mathrm{t}}$. 15.3 min., the mass spectrum displayed a molecular ion peak $\mathrm{M}^{+}$at $m / z(\%$ relative abundance), $=237(5 \%)$ correspond to the molecular formula $\mathrm{C}_{8} \mathrm{H}_{15} \mathrm{O}_{3} \mathrm{NS}_{2}$. Other fragments at 236( $\left.\mathrm{M}^{+}-1,12.3 \%\right), 221\left(\mathrm{M}^{+}-\mathrm{CH}_{4}, 28.6 \%\right), 204\left(\mathrm{M}^{+}-\right.$ 
$\mathrm{SH}, 17.5 \%), 180\left(\mathrm{M}^{+}-\mathrm{NCS}, 74 \%\right), 165\left(\mathrm{M}^{+}-\mathrm{CH}_{2} \mathrm{NCS}, 100 \%\right), 137\left(\mathrm{M}^{+}-\left(\mathrm{CH}_{2}\right)_{3} \mathrm{NCS}, 32 \%\right), 123\left(\mathrm{M}^{+}-\left(\mathrm{CH}_{2}\right)_{4} \mathrm{NCS}_{1}, 12.5 \%\right), 109\left(\mathrm{M}^{+}-\left(\mathrm{CH}_{2}\right)_{5} \mathrm{NCS}_{1}, 18 \%\right)$ and $91\left(\mathrm{M}^{+}-\left[\mathrm{H}_{2} \mathrm{O}+\left(\mathrm{CH}_{2}\right)_{5} \mathrm{NCS}\right], 11.8 \%\right)$ or $\left(\mathrm{M}^{+}-\left[\mathrm{CH}_{3} \mathrm{SO}_{2}-\mathrm{CH}-1\right]\right)$. The latter two fragments $(\mathrm{m} / \mathrm{z} 91$ and 109$)$ showed the presence of the OH group at $\mathrm{C}-6$ and the fragmentation pattern proved the identification of the aglucone as 6-methylsulfonyl-6-hydroxy hexy/ ITC $\left[\mathrm{CH}_{3} \mathrm{SO} \mathbf{2}_{2}-\mathrm{CH}(\mathrm{OH})-(\mathrm{CH})_{4}-\right.$ $\mathrm{CH}_{2}$ - NCS] (Chart 2).

FA2- 4-pentenyl ITC. $\mathrm{R}_{\mathrm{t}}$. 14.4 min., the molecular ion peak $\mathrm{M}^{+}$was present at $\mathrm{m} / \mathrm{z}=127(14.3 \%)$ which correspond to the molecular formula $\mathrm{C}_{6} \mathrm{H}_{9} \mathrm{NS}$. Another important fragments at $\mathrm{m} / z 100\left(\mathrm{M}^{+}-\left(\mathrm{CH}_{2}=\mathrm{CH}^{+}, 18 \%\right), 85\left(\mathrm{M}^{+}-\left(\mathrm{CH}_{2}\right)_{3}, 76 \%\right)\right.$ and $57\left(\mathrm{M}^{+}-\left(\mathrm{CH}_{2}=\mathrm{CH}-\left(\mathrm{CH}_{2}\right)_{3}, 100 \%\right)\right.$. These data substantiate the identification of the compound as 4-pentenyl ITC $\mathrm{CH}_{2}=\mathrm{CH}-\left(\mathrm{CH}_{2}\right)_{3}-\mathrm{NCS}($ Chart 2).

FA3- 3-Methylthio propyl ITC, $\mathrm{R}_{\mathrm{t}} .16 .9$ min., the mass spectrum gave $\mathrm{M}+$ at $\mathrm{m} / \mathrm{z}$ of $147(12 \%)$ which fit with the molecular formula $\mathrm{C}_{5} \mathrm{H}_{9} \mathrm{NS}_{2}$. The peaks at $\mathrm{m} / \mathrm{z} 101\left(\mathrm{M}+-\mathrm{CH}_{3} \mathrm{~S}, 100 \%\right), 86\left(\mathrm{M}+-\mathrm{CH}_{3} \mathrm{~S}-\mathrm{CH}_{2}, 2 \%\right), 72\left(\mathrm{M}+-\mathrm{CH}_{3} \mathrm{~S}-\mathrm{CH}_{2}-\mathrm{CH}_{2}, 50 \%\right)$ and $61\left(\mathrm{M}+--\mathrm{CH}_{2}-\mathrm{CH}_{2}-\mathrm{NCS}, 44 \%\right)$ confirmed the presence of a methylthio unit attached to a propyl group and the compound identified as 3-Methylthio propyl ITC $\mathrm{CH}_{3} \mathrm{~S}-\mathrm{CH}_{2}-\mathrm{CH}_{2}-\mathrm{CH}_{2}-\mathrm{NCS}$ (Chart 2).

FA4- 5-hydroxypentyl ITC. $\mathrm{R}_{\mathrm{t}}$. $19.2 \mathrm{~min}$, the mass spectrum of this compound showed $\mathrm{M}^{+}$at $\mathrm{m} / \mathrm{z}=145(3 \%)$ correspond to the molecular formula $\mathrm{C}_{6} \mathrm{H}_{11} \mathrm{ONS}$. The fragments at $101\left(\mathrm{M}^{+}-\left(\mathrm{CH}_{2}-\mathrm{OH}\right), 22.5 \%\right), 87\left(\mathrm{M}^{+}-\mathrm{NCS}, 20.6 \%\right), 73\left(\mathrm{M}^{+}-\mathrm{CH}_{2}-\mathrm{NCS}_{,} 67.8 \%\right)$ and $59\left(\mathrm{M}^{+}-\left[\mathrm{CH}_{2}-(\mathrm{OH}) \mathrm{CH}_{2} \mathrm{CH}_{2}\right.\right.$, $100 \%$ ) confirm the identification of the aglucone as 5-hydroxypentyl ITC $\left[\mathrm{CH}_{2}(\mathrm{OH})-\left(\mathrm{CH}_{2}\right)_{3}-\mathrm{CH}_{2}-\mathrm{NCS}\right](\mathrm{Chart} 2)$.

FA5- sulphoraphane (4-methylsulphinyl butyl ITC): $\mathrm{R}_{\mathrm{t}}$. $28.7 \mathrm{~min}$., the $\mathrm{MS}$ of the compound revealed the presence of $\mathrm{M}^{+}$at $m / z=177$ corresponding to $\mathrm{C}_{6} \mathrm{H}_{11} \mathrm{ONS}_{2}$ as a molecular formula. The fragmentation giving rise to $114\left(\mathrm{M}^{+}-\mathrm{CH}_{3} \mathrm{SO}-, 6 \%\right), 86\left(\mathrm{M}^{+}-\mathrm{CH}_{3} \mathrm{SO}-\mathrm{CH}_{2}, 5 \%\right)$ and 72 $\left(\mathrm{M}^{+}-\mathrm{CH}_{2} \mathrm{NCS}, 100 \%\right)$. So the compound was identified as 4-methylsulphinyl butyl ITC, $\mathrm{CH}_{3} \mathrm{SO}-\left(\mathrm{CH}_{2}\right)_{4} \mathrm{NCS}(\mathrm{Chart} 2)$.

The variation of glucosinolate hydrolysis products between previous studies and the present work may be due to geographical and seasonal differences, environment, soil type, stress and plant part examined, or due to the differences in the experimental conditions.

\subsection{Computational studies:}

\subsubsection{Frontier orbital analysis:}

"FMOs" frontier molecular orbitals through two types HOMO (donating electron) and LUMO (accepting electron) are a crucial orbitals for molecule. This orbitals able to display the binding manner of biomolecule with receptor. FMOs gap was characterized the chemical reactivity and kinetic stability of the molecule[19, 20].

Figure 1

The HOMO was localized over methyl(prop-1-en-1-yl)sulfane region with (Fig. 1), while sulfanecarbaldehyde 0-((oxidaneyl)dioxo-I6-sulfaneyl) oxime fragment covered by LUMO zone. Thus, the electrons transition (HOMO $\rightarrow$ LUMO) from sulfonyl to sulfonyl groups. The low $\triangle \mathrm{G}$ enhance the interaction between HOMO ligand and the LUMO receptor (Table 1), with inversed mode was took place [20]. The charge transfer was represented the reactivity index term " $\Delta \mathrm{N}_{\text {max }}$ ", which was restricted by the stabilization energy during the system was gained charge from the biological media (Table 1). The low softness value may be combined with a high potential against biological environment (Table 2). 
Table 2

Calculated energetic global reactivity parameters 4-methythio-3-butenyl gluconate at DFT with a B3LYP\6-311G* Basics sets

\begin{tabular}{|c|c|c|}
\hline E & -1554.78 & \multirow{15}{*}{$\begin{array}{l}\text { E: The total energy (Kcal/mol)., HOMO: Highest Occupied Molecular Orbital (eV), LUMO: Lowest Occupied Molecular } \\
\text { Orbital }(\mathrm{eV}), \Delta \mathrm{G} \text { : difference between HOMO and LUMO energy levels(eV), I: Ionization potential, A; electron affinity; } \eta \text { : } \\
\text { Hardness }(\mathrm{eV}), \mathrm{S} \text { : Softness }(\mathrm{eV}), \mathrm{X} \text { : Electronegativity }(\mathrm{eV} ; \mu+: \text { electron accepting chemical potentials, } \mu-: \text { electron } \\
\text { donating chemical potentials, } \mu+\text { chemical potential }(\mathrm{eV}), \omega+: \text { electron accepting capacity, } \omega \text {-: Electrodonating } \\
\text { capacity; } \omega^{ \pm:}: \text {Electrophilicity index in valance state }(\mathrm{eV}) ; \Delta \mathrm{N}_{\text {max }} \text { : maximum number of electrons transfer. }\end{array}$} \\
\hline HOMO & -9.23 & \\
\hline LUMO & -1.39 & \\
\hline$\Delta \mathbf{G}$ & -7.84 & \\
\hline I & 9.23 & \\
\hline A & 1.39 & \\
\hline$\eta$ & 3.92 & \\
\hline$S$ & 0.255 & \\
\hline$x$ & -5.31 & \\
\hline$\mu+$ & -3.35 & \\
\hline$\mu-$ & -7.027 & \\
\hline$\omega-$ & 6.741 & \\
\hline$\omega^{+}$ & 3.106 & \\
\hline$\omega^{ \pm}$ & 9.847 & \\
\hline$\Delta \mathrm{N}_{\mu \mathrm{a \xi}}$ & 1.354 & \\
\hline
\end{tabular}

The ligand exhibited that (Table 1), high electrophilicity value " $\omega \pm=6.741$ ", rising of the electron donating power ( $\mu-=7.02 \mathrm{ev})$ with increasing donating capacity $\left(\omega^{-}=6.74 \mathrm{ev}\right)$. The high electrophilicity for ligand may be led to increasing attacking power against a polar residue in the receptor, which increase the potency.

\subsubsection{Molecular electrostatic potential (MEP)}

The repulsive and attractive forces were figured by the molecular electrostatic potential (MEP) for 4-methylthio-3-butenylglucosinolate (Fig. 1). Orange, yellow, red colors depicted a high electron density area, while the blue color represented the positive potential, and green color represented the intermediate potential value. The negative charge capped the most area of the molecule, while formaldhydoxime area covered by positive charge. The variation of color in MEP surface linked with difference in electrostatic potential. this force accountable for identification of the substrate with receptor binding site, and hence promotion the electrostatic bond between substrate-receptor[21].

\subsection{Docking studies:}

The docking study have targeted a a-glucosidase and $\beta$-amylase, to examine a mode of action of the 4-methylthio-3-butenylglucosinolate. The ligand-protein interaction behavior were estimated based gold score function as implemented in MOE 2015.10[22]. All calculations of docking experiment were represented (Table 2). The crystal structures for a-glucosidase(PDB: 4yvx[23]) and a-amylase(PDB: 4gqr[24]) have been obtained from protein databank, which their complexed with Glimipride and myricetin as reference drugs, respectively. The tested ligand docked into active site for two enzymes.

Figure 2:

The active site of these enzymes were defined to include residues within a $3.5 \AA$ radius around reference drugs atoms. The molecular dynamic (MD) using (MMFF94) force field to $0.05 \mathrm{Kcal} / \mathrm{mol}$ gradient convergence range, which their was applied to minimize energy for obtained ligandenzyme complexes. The binding affinity for the tested ligand was determined by highest MOE scoring function (Table 3 ). The premier ligands revealed MOE score $(-7.511$ and $-6.157 \mathrm{Kcal} / \mathrm{mol})$, respectively, for a-glucosidase and $\beta$-amylase. In a-glucosidase binding site, Glimipride make important strong hydrogen bond with His117 and Tyr55, at the time this ligand forms $\pi-\pi$ bonds with Tyr24 and Trp22. The analysis binding site of $\beta$-amylase-Myricetin pose exhibited that, the ligand interacted with important amino acid backbone as Asp197, which contacted with 2-H-bonds. The tested compound exhibited a higher binding affinity with MOE scores $(-6.611 \mathrm{Kcal} / \mathrm{mol}$.) than reference drug (-6.115 $\mathrm{Kcal} / \mathrm{mol}$.). This ligand was formed an important hydrogen bond with important Asp amino acid (Fig. 3). Our compound arranged in binding pock at parallel mode with Asp ( Fig. 3). 
Table 3

Docking energy scores (Kcal/mol) derived from the MOE for 4-methythio-3-butenyl gluconate.

\begin{tabular}{|c|c|c|c|c|}
\hline \multirow[t]{2}{*}{ Enzyme } & \multicolumn{2}{|l|}{$4 y v x$} & \multicolumn{2}{|l|}{$4 \mathrm{gqr}$} \\
\hline & Glimipride & Tested Ligand & myricetin & Tested Ligand \\
\hline$E_{\text {-score } 1}$ & -7.75118 & -7.11842 & -101.157 & -131.364 \\
\hline E. $d_{G E}$ & 1.62884 & 1.122716 & -5.19 & -7.209 \\
\hline$E_{-c o n f}$ & -263.798 & 85.79013 & -101.987 & -117.44 \\
\hline$E_{\text {-place }}$ & -49.6922 & -104.664 & -367.2 & -566.262 \\
\hline E.Int· & -13.9234 & -14.7619 & -101.987 & -117.44 \\
\hline E.н.в. & -42.0326 & -39.5142 & -37.74 & -56.14 \\
\hline Eele & -7.75118 & -7.11842 & -3.07 & -3.6 \\
\hline Evdw & -7.49118 & -7.28842 & 2.59 & 3.24 \\
\hline RMS & 1.62884 & 1.122716 & 0.9652 & 0.865 \\
\hline \multicolumn{5}{|c|}{ 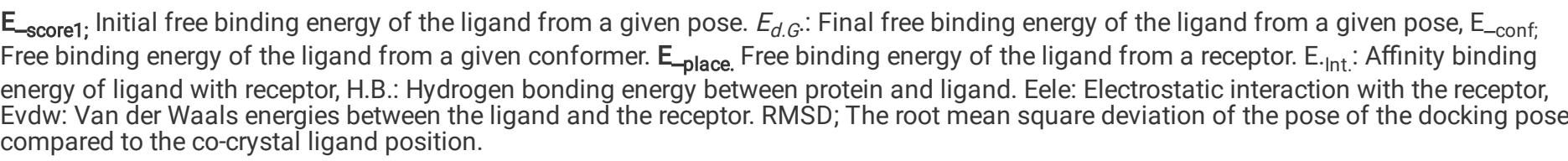 } \\
\hline
\end{tabular}

The hydrophilicity of binding pocket is postulated that, the hydrophobicity and membrane permeability are an important pharmacokinetic character for absorption molecule in biological system. The results clearly revealed that, the amino acid residues close to the reference molecules are mostly the same as observed in the tested compound.

Figure 3 :

\subsection{In silico Toxicological study}

\subsubsection{In silico pharmacokinetic Profile:}

Cytotoxicity screening in silico through ADMET parameters acting a fundamental route in therapeutic bioactive molecule. The calculated descriptors for 4-methylthio-3-butenylglucosinolate and Glimipride were calculated by MOE, SwissADME [25] and admet-SAR model[26], which these disclosed in (Table 4). The physicochemical and ADME parameters for 4-methythio-3-butenyl glucosinolate Glimipride (reference drug), which stated that this ligand suitable for Lipinski's rule with one violation related to molecular weight. Furthermore, when applied Ghose Veber, Egan and Muegge rules, the tested compounds don't passed these rules, except Glimipride drug is qualified for Muegge rule. Consequently, the tested compound exhibited bioavailability Scores ( 0.11 and 0.55$)$ with biodegradation values $(0.6362$ and 0.4523$)$. These data confirmed that the investigated compound have good oral bioavailability. The lead-likeness profile plotted the Bioavailability Radar planner for tested compound (Fig. 4). The reader figured relation between polarity, size, lipophilicity, solubility, saturation and flexibility[20], the optimal range for each parameters represented in pink color. From the first glance for the reader, 4-methythio-3-butenyl glucosinolate and Glimipride exhibited deviation for polarity and flexibility, respectively, (Fig. 4). 
ADMET(absorption, distribution, metabolism, and excretion - toxicity ) for 4-methythio-3-butenyl gluconate and Glimipride.

\begin{tabular}{|c|c|c|c|c|c|c|c|}
\hline & Ligand & Glimipride & & & Ligand & Glimipride & \\
\hline $\begin{array}{l}\text { Molecular } \\
\text { weight }\end{array}$ & 434.48 & 490.62 & \multirow{8}{*}{$\begin{array}{l}\text { Physicochemical } \\
\text { Properties }\end{array}$} & Log Po/w (iLOGP) & 2.8 & 2.42 & \multirow[t]{5}{*}{$\begin{array}{l}\text { Lipophilicity } \\
\text { parameters }\end{array}$} \\
\hline $\begin{array}{l}\text { Num. heavy } \\
\text { atoms }\end{array}$ & 26 & 34 & & Log Po/w (XLOGP3) & 1.38 & 3.85 & \\
\hline $\begin{array}{l}\text { Num. arom. } \\
\text { heavy atoms }\end{array}$ & 0 & 6 & & Log Po/w (WLOGP) & 0.42 & 3.77 & \\
\hline Fraction Csp3 & 0.75 & 0.54 & & Log Po/w (MLOGP) & 2.37 & 1.88 & \\
\hline $\begin{array}{l}\text { Num. rotatable } \\
\text { bonds }\end{array}$ & 9 & 11 & & $\begin{array}{l}\text { a Consensus } \\
\text { Log } P_{o / w}\end{array}$ & 1.84 & 2.76 & \\
\hline $\begin{array}{l}\text { Num. H-bond } \\
\text { acceptors, } \\
\text { donner }\end{array}$ & 10,5 & 5,3 & & Lipinski & $\begin{array}{l}\text { Yes; } \\
\text { violation = 1; } \\
\text { No rO }<10\end{array}$ & $\begin{array}{l}\text { Yes; } 0 \\
\text { violation }\end{array}$ & \multirow[t]{6}{*}{$\begin{array}{l}\text { Drug } \\
\text { likeness }\end{array}$} \\
\hline $\begin{array}{l}\text { TPSA } \\
\text { (Topological } \\
\text { surface area) }\end{array}$ & $186.32 A^{2}$ & $133.06 \mathrm{~A}^{2}$ & & Ghose & $\begin{array}{l}\text { No; } \\
\text { violation = } \\
1: \\
\text { WLOGP>-0.4 }\end{array}$ & $\begin{array}{l}\text { No; } 2 \\
\text { violations: } \\
M W>480 \text {, } \\
M R>130\end{array}$ & \\
\hline $\begin{array}{l}\text { Absorption } \\
\text { percentage }\end{array}$ & 44.48 & 63.09 & & Veber & $\begin{array}{l}\text { No; } \\
\text { violation = } \\
\text { 1: } \\
\text { TPSA140< }\end{array}$ & $\begin{array}{l}\text { No; } 1 \\
\text { violation: } \\
\text { Rotors > } 10\end{array}$ & \\
\hline Mutagenic & none & none & \multirow[t]{10}{*}{$\begin{array}{l}\text { Pharmacokinetics } \\
\text { parameters }\end{array}$} & Egan & $\begin{array}{l}\text { No; } \\
\text { violation = } \\
\text { 1: } \\
\text { TPSA131.6< }\end{array}$ & $\begin{array}{l}\text { No; } 1 \\
\text { violation: } \\
\text { TPSA > } 131.6\end{array}$ & \\
\hline Tumorigenic & none & none & & Muegge & $\begin{array}{l}\text { No violation } \\
=2: \text { TPSA< } \\
150 \mathrm{H} \text {, acc }< \\
10\end{array}$ & Yes & \\
\hline Carcinogens & None & None & & $\begin{array}{l}\text { Bioavailability } \\
\text { Score }\end{array}$ & 0.11 & 0.55 & \\
\hline $\begin{array}{l}\text { Reproductive } \\
\text { Effective }\end{array}$ & high & high & & PAINS & 0 alert & 0 alert & \multirow[t]{4}{*}{$\begin{array}{l}\text { Medicinal } \\
\text { chemistry }\end{array}$} \\
\hline Irritant & low & low & & bBrenk & 0 alerts & 0 alert & \\
\hline $\begin{array}{l}\text { HIA (Human } \\
\text { Intestinal } \\
\text { Absorption) }\end{array}$ & 0.9893 & 0.6412 & & Leadlikeness & $\begin{array}{l}2 \text { violations: } \\
\text { MW > 350, } \\
\text { Rotors > } 7\end{array}$ & $\begin{array}{l}3 \text { violations: } \\
M W>350, \\
\text { Rotors >7, } \\
\text { XLOGP3 > } 3.5\end{array}$ & \\
\hline $\begin{array}{l}\text { Caco2- } \\
\text { Permeability }\end{array}$ & 0.5734 & 0.68523 & & $\begin{array}{l}\text { Synthetic } \\
\text { accessibility }\end{array}$ & 5.66 & 4.71 & \\
\hline hERG_inhibition & ambiguous & ambiguous & & $\log S$ (ESOL) & -1.07 & -4.71 & \multirow{3}{*}{$\begin{array}{l}\text { water } \\
\text { solubility }\end{array}$} \\
\hline $\begin{array}{l}\text { BBB(blood } \\
\text { brain barrier } \\
\text { Permeability) }\end{array}$ & No & No & & Solubility & $\begin{array}{l}0.36 \mathrm{mg} / \mathrm{ml} ; \\
0.85 \times 10^{-2} \\
\mathrm{~mol} / \mathrm{l}\end{array}$ & $\begin{array}{l}9.52 \times 10-3 \\
\mathrm{mg} / \mathrm{ml} ; 1.94 \\
\times 10-5 \mathrm{~mol} / \mathrm{l}\end{array}$ & \\
\hline Biodegradation & 0.6362 & 0.4523 & & $\begin{array}{l}\text { Qualitative } \\
\text { solubility }\end{array}$ & Very soluble & $\begin{array}{l}\text { Poorly } \\
\text { soluble }\end{array}$ & \\
\hline
\end{tabular}

a Consensus Log $\mathrm{P}_{\mathrm{o} / \mathrm{w}}$ : average four prediction of partition coefficient between n-octanol- water.

bhet-C-het_not_in_ring, imine_1, imine_2, oxygen-nitrogen_single_bond

${ }^{\mathrm{c}}$ In vitro Ames test result for each TA100 strain (Metabolic activation by rat liver homogenate), TA100 strain (No metabolic activation), TA1535 strain (Metabolic activation by rat liver homogenate) and TA1535 strain (No metabolic activation)[9].

d Toxicity Class ranging from 1 to 6 according to the Global Harmony System (GHS) [8]. 


\begin{tabular}{|c|c|c|c|c|c|c|}
\hline & Ligand & Glimipride & & Ligand & Glimipride & \\
\hline Gl absorption & Low & Low & cAMES Toxicity & None & None & \multirow{8}{*}{$\begin{array}{l}\text { toxicity } \\
\text { prediction }\end{array}$} \\
\hline P-gp substrate & Yes & Yes & Acute Oral Toxicity & None & None & \\
\hline $\begin{array}{l}\text { CYP1A2 } \\
\text { inhibitor }\end{array}$ & No & No & LD50 & $16 \mathrm{mg} / \mathrm{kg}$ & $3250 \mathrm{mg} / \mathrm{mol}$ & \\
\hline $\begin{array}{l}\text { CYP2C19 } \\
\text { inhibitor }\end{array}$ & No & No & $\begin{array}{l}\text { dPredicted Toxicity } \\
\text { Class }\end{array}$ & 2 & 5 & \\
\hline $\begin{array}{l}\text { CYP2C9 } \\
\text { inhibitor }\end{array}$ & No & Yes & Average similarity\% & 34.27 & 60.83 & \\
\hline $\begin{array}{l}\text { CYP2D6 } \\
\text { inhibitor }\end{array}$ & No & No & $\begin{array}{l}\text { Prediction } \\
\text { accuracy\% }\end{array}$ & 23 & 68.07 & \\
\hline $\begin{array}{l}\text { CYP3A4 } \\
\text { inhibitor }\end{array}$ & No & Yes & Binding to Toxicity & $\begin{array}{l}\text { No binding } \\
\text { targets }\end{array}$ & $\begin{array}{l}\text { No binding } \\
\text { targets }\end{array}$ & \\
\hline $\begin{array}{l}\text { Log Kp (skin } \\
\text { permeation) }\end{array}$ & $-9.93 \mathrm{~cm} / \mathrm{s}$ & $-6.56 \mathrm{~cm} / \mathrm{s}$ & Toxic fragments & Nil. & Nil. & \\
\hline
\end{tabular}

a Consensus Log $\mathrm{P}_{\mathrm{o} / \mathrm{w}}$ : average four prediction of partition coefficient between n-octanol-water.

bhet-C-het_not_in_ring, imine_1, imine_2, oxygen-nitrogen_single_bond

${ }^{\mathrm{C}}$ In vitro Ames test result for each TA100 strain (Metabolic activation by rat liver homogenate), TA100 strain (No metabolic activation), TA1535 strain (Metabolic activation by rat liver homogenate) and TA1535 strain (No metabolic activation)[9].

d Toxicity Class ranging from 1 to 6 according to the Global Harmony System (GHS) [8].

Both compounds showed high saturation degree(Fraction Csp3 $=0.75,0.45$, respectively), which pass the filter of Fraction Csp3 $<0.25[27]$. The solubility parameters are important key for absorption, the 4-methythio-3-butenyl glucosinolate exhibited strong soluble in $\mathrm{H}_{2} \mathrm{O}$ when applied ESOL topological model with absorption\% (\%ABS = 44.48)[28], in contrary Glimipride showed poor solubility in this model (Table 4). Also, lipophilicity parameters in medicinal chemistry incorporated as lead-likeness filter, which identified problematic fragments in bioactive molecules based on two Structural alerts as PAINS and Brenk's filters [20]. The tested compounds exhibited no structural alerts against PAINS and Brenk's filters.

Figure 4

Mutagenic, Tumorigenic, Reproductive Effective, Irritant, Human Intestinal absorption, were investigated in silico using admet-sar pharmacokinetic parameters[29]. Furthermore, the other (SVM) algorithm was applied to identify substrate or non-substrate of the permeability for skin permeation (Log Kp), Caco-2, blood brain barrier (BBB) and p-glycoprotein (P-gp), as well as, to recognize inhibition effect against the chief cytochromes P450 isoenzymes (CYP1A2, CYP2C19, CYP2C9, CYP2D6, CYP3A4). The results obtained from (Table 3) exhibited that, Glimipride drug inhibited both CYP2C9 and CYP3A4, but our tested ligand has no inhibition action for all types of P450. The BOILED-Egg model is represented relation for WLOGP vs TPSA in (Fig. 4), which demonstrated that, High BBB permeability, high GI absorption, high brain penetration, ambiguous inhibition action for against human Ether-à-go-go-Related Gene (hERG). In addition, the Glimipride showed activation action against P-gp (multidrug resistance protein 1), but our compound act as P-gp inhibitor. Furthermore, skin permeability (Kp) was predicted for our compounds, which described that, the higher negative value combined with low skin permeability for compounds. The data in (Table 4) showed that, the Glimipride drug is higher skin permeability than our ligand. The carcinogen behavior was investigated by admet-sar for the investigated compounds, through compared with 981 various carcinogenic chemical structures, that obtained from "Carcinogenic Potency Database (CPDB [30])", the results exhibited no carcinogenicity, mutagenicity and tumorigenicity effects for tested compounds.

\subsubsection{Oral toxicity prediction:}

The possible toxicity was predicted[31], through calculate estimate rodent oral toxicity based on extracted from the Chemical European Biology Laboratory (ChEMBL) database[26]. Also, median lethal doses $\left(\mathrm{LD}_{50}\right)$ values was estimated in rodents, which our ligand (LD50 =

$16 \mathrm{mg} / \mathrm{Kg})$ showed lower value than reference drug $\left(\mathrm{LD}_{50}=3250 \mathrm{mg} / \mathrm{Kg}\right)$. The calculated toxicity using this database depend on highest endpoints including of 33 models (Table 4). The calculated schematic is devided into several stages of toxicity as "toxicity, toxicological endpoints (mutagenicity, carcinotoxicity, organ toxicity (hepatotoxicity), cytotoxicity and immunotoxicity), toxicological pathways (AOPs) and toxicity targets thereby"[25], which provided a suitable visions into the possible molecular mechanism as well as toxic response (Table 5). The Glimipride located in lower toxicity classes 5 than 4-methythio-3-butenyl glucosinolate, which sited in Class (No. 4), while both compounds do 
not exhibited any toxic fragments without non-binding to any toxicity targets(Table 5). In general, the tested compounds have been a good oral bioavailability, high ability $B B B$ transport, and no marked health effects observed for rodent toxicity profiles.

Table 5: Toxicity Model Report for ligand which extracted from admet-SAR.

\begin{tabular}{|c|c|c|c|c|c|c|}
\hline Classification & Target & Shorthand & Prediction & Probability & Prediction & Probability \\
\hline & & & & Glucosanate & & Glimipride \\
\hline Organ toxicity & Hepatotoxicity & dili & Inactive & 0.62 & Inactive & 0.71 \\
\hline Toxicity end points & Carcinogenicity & carcino & Inactive & 0.56 & Inactive & 0.72 \\
\hline Toxicity end points & Immunotoxicity & immuno & Inactive & 0.84 & Inactive & 0.99 \\
\hline Toxicity end points & Mutagenicity & mutagen & Inactive & 0.58 & Inactive & 0.76 \\
\hline Toxicity end points & Cytotoxicity & cyto & Inactive & 0.7 & Inactive & 0.64 \\
\hline Tox21-Nuclear receptor signaling pathways & Aryl hydrocarbon Receptor (AhR) & nr_ahr & Inactive & 0.91 & Inactive & 0.97 \\
\hline $\begin{array}{r}\text { Tox21-Nuclear receptor } \\
\text { signaling pathwvays }\end{array}$ & Androgen Receptor (AR) & nr_ar & Inactive & 0.9 & Inactive & 0.98 \\
\hline $\begin{array}{r}\text { Tox21-Nuclear receptor } \\
\text { signaling pathwvays }\end{array}$ & $\begin{array}{l}\text { Androgen Receptor Ligand } \\
\text { Binding Domain (AR-LBD) }\end{array}$ & nr_ar_lbd & Inactive & 0.96 & Inactive & 0.96 \\
\hline $\begin{array}{r}\text { Tox21-Nuclear receptor } \\
\text { signaling pathwvays }\end{array}$ & Aromatase & nr_aromatase & Inactive & 0.92 & Inactive & 0.97 \\
\hline $\begin{array}{r}\text { Tox21-Nuclear receptor } \\
\text { signaling pathwways }\end{array}$ & Estrogen Receptor Alpha (ER) & nr_er & Inactive & 0.83 & Inactive & 0.96 \\
\hline $\begin{array}{r}\text { Tox21-Nuclear receptor } \\
\text { signaling pathwvays }\end{array}$ & $\begin{array}{r}\text { Estrogen Receptor Ligand } \\
\text { Binding Domain (ER-LBD) }\end{array}$ & nr_er_lb|d & Inactive & 0.91 & Inactive & 0.99 \\
\hline $\begin{array}{r}\text { Tox21-Nuclear receptor } \\
\text { signaling pathwvays }\end{array}$ & $\begin{array}{l}\text { Peroxisome Proliferator Activated } \\
\text { Receptor Gamma (PPAR-Gamma) }\end{array}$ & nr_Ppar_gamma & Inactive & 0.96 & Inactive & 0.95 \\
\hline $\begin{array}{r}\text { Tox21-Stress response } \\
\text { pathwvays }\end{array}$ & $\begin{array}{l}\text { Nuclear factor (erythroid-derived 2)-like 2/ } \\
\text { antioxidant responsive element (nrf2/ARE) }\end{array}$ & sr_are & Inactive & 0.96 & Inactive & 0.99 \\
\hline Tox21-Stress response pathways & Heat shock factor response element (HSE) & sr_hse & Inactive & 0.96 & Inactive & 0.99 \\
\hline Tox21-Stress response pathways & Mitochondrial Membrane Potential (MMP) & sr_mmp & Inactive & 0.92 & Inactive & 0.85 \\
\hline Tox21-Stress response pathways & Phosphoprotein (Tumor Supressor) p53 & sr_p53 & Inactive & 0.93 & Inactive & 0.96 \\
\hline Tox21-Stress response pathways & $\begin{array}{r}\text { ATPase family AAA } \\
\text { domain-containing protein } 5 \text { (ATAD5) }\end{array}$ & sr_atad5 & Inactive & 0.98 & Inactive & 0.99 \\
\hline
\end{tabular}

\section{Material And Methods}

\subsection{Plant Materials:-}

The aerial parts of both plants (Carrichtera annua (L.) DC. and Farsetia aegyptia Turra) were collected from Alariesh airport region (North Saini governerate) and wadi Hagol (at Cairo-Sues road, km-30), respectively through the flowering stage at the end of winter season (25-march). The plants were kindly, identified by prof. Dr. Ibrahim Elgarf, prof. of taxonomy at botany dept., faculty of science, Cairo univ. and the voucher specimens were deposited at NRC herbarium. Each plant was air dried and grounded to a fine powder.

\subsection{Instruments and Reagents:}

${ }^{1} \mathrm{H}$ and ${ }^{13} \mathrm{C}$ NMR spectra were measured using Joel JNM EX270FTNMR system at $270 \mathrm{MHz}$ for ${ }^{1} \mathrm{H}$ and $70 \mathrm{MHz}$ for ${ }^{13} \mathrm{C}$ at the central lab. For services, NRC, Cairo, Egypt. The sample was dissolved in DMSO and the chemical shifts are given in $\delta(\mathrm{ppm})$ relative to tetramethylsilane $\left(\mathrm{Me}_{4} \mathrm{Si}\right.$ ).UV spectra were recorded on Shimadzu model UV-240 and 2401 PC spectrophotometer (Shimadzu Inc., Tokyo, Japan) in methanol in the range $200-450 \mathrm{~nm}$.

\subsection{Conditions for GC/MS analysis of the isothiocyanates:}

\subsubsection{Apparatus:}

- GC/MS Finning an SSQ7000, Digital DEC3000 with column: DB5 capillary (I.d.0.25 mm), ionization mode: El at 70ev, temperature program start at : $50^{\circ} \mathrm{C}$ up to $250{ }^{\circ} \mathrm{C}$ with a rate of $4{ }^{\circ} \mathrm{C} / \mathrm{min}$., Detector. MS, sample volume $2 \mu \mathrm{l}$ and the mass from $40-400$.

- modified silver nitrate reagent [12] in which the Gls. appears as brownish spots on a yellowish background.

- Solvent systems: S1, Butanol: acetic acid : water 4:1:5 upper layer(which contain the organic solvent saturated with water) and S2, Butanol: ethanol: water 4:1:3. Acidic aluminium oxide (anionotropic $1.5 \mathrm{~kg}$, activity grade I, type WA-I acidic, Sigma chemical Co.), Cellulose for column (Merck, 64271 Darmstadt, Germany) and DEAE Sephadex A-25 (Germany). myrosinase enzyme (Thioglucosidase, Sigma, T $4528)$.

Extraction and Isolation of Glucosinolates:

- About $2.0 \mathrm{~kg}$ of air dried powdered herb of both C. annua and F. aegyptia were defatted, separately, with petroleum ether(br. $\left.40-60{ }^{\circ} \mathrm{C}\right)$ in a Soxhlet apparatus for three days (operate 12 hrs. daily). The defatted powders were air dried and extracted (separately) with methyl 
alcohol $\left(80 \%, 3 \times 3 \mathrm{~L}, 3\right.$ days each ), the combined methanol extract of each plant was evaporated in vacuo at $40^{\circ} \mathrm{C}$ and the residues were dissolved in hot distilled water $(750 \mathrm{ml})$, left in the refrigerator for $24 \mathrm{hrs}$. and filtered the gummy ppt.. The aqueous filtrates were allowed to pass slowly through an acidic aluminium oxide column (Aluminium oxide, for chromatography, acidic, Brockmann I, 50-200 $\mu$ m, $60 \mathrm{~A}$, Acros Organics, Fluca, $7.5 \times 60)$ to remove the coloring matters, then, the total Gls were eluted with potassium sulfate solution $(2 \%$, $2.5 \mathrm{~L})$ till the brown zone(containing the total glucosinolates ) reached the bottom of the column, the eluate containing the brown zone was evaporated under reduced pressure till dryness. The residue for each plant was dissolved with hot methanol, filtered through centered glass funnel (G3) and evaporated in vacuo at $40{ }^{\circ} \mathrm{C}$ till dryness to give a faint brownish residue ( $2.1 \mathrm{~g}$ for CA and $500 \mathrm{mg}$ for FA)

\subsection{Purification of Gls :}

The obtained brownish residue was further purified using cellulose column eluted with the upper layer of the solvent S2, after the complete elution, the eluate was concentrated and subjected to preparative paper chromatography (PPC) using chromatographic paper Whatmann 3 mm developed in the upper layer of solvent S1 (two runs) applying the descending technique. Two main zones were determined with pencil cut into small pieces and eluted with methanol (90\%). Each zone was further purified over DEAE Sephadex A-25 column eluted with $0.5 \%$ ammonium acetate soln., to afford two compounds (CA1 and CA2, $\mathrm{R}_{\mathrm{b}} 0.52$ and 0.65 , relative to benzyl Gls, $17 \mathrm{mg}$ and $3 \mathrm{mg}$ respectively).

\subsection{Enzymatic hydrolysis of Gls:}

Due to the small amounts of the compound A2 and the residue of total Gls from FA, so, compound A2 and the total Gls from FA were subjected, separately, to enzymatic hydrolysis using myrosinase enzyme. The aqueous acidic solution after separation of the aglucones was neutralized with barium carbonate and filtered. The clear filtrate was evaporated till dryness. The residue was dissolved in $10 \%$ isopropanol and subjected to paper chromatography using ethyl acetate : pyridine: water (12: 5: 4) as developing solvent and different authentic sugars. The chromatogram was visualized by spraying with aniline phthalate, and heated at $105^{\circ} \mathrm{C}$ for few minutes. Only glucose was detected as a sugar and the presence of sulfate ions in the aqueous solution were detected by addition of few drops of barium chloride soln., where a white ppt. was noticed proving the presence of sulphate ions.

Also, the total Gls. were extracted from F. aegyptia using the same method and they were purified using PPC with different solvents and repeated Sephadex LH-20 columns to afford five compounds in small amounts so, they subjected to enzymatic hydrolysis as before, and the hydrolysis products were extracted with ether and identified by GC/MS. The aqueous layer was found to contain glucose and sulphate ions.

\subsection{Computational study:}

\subsubsection{Preparation of Small Molecule:}

The target compound was built and minimized using the PM3 semi-empirical Hamiltonian molecular orbital calculation MOPAC16 package[32], then employing density function theory in Gaussian 09 program package[28] with the Becke3-Lee-Yang-parr (B3LYP) level using 6-311G* basis as implemented in MOE 2015 package[17]. The optimization Geometry for molecular structures were carried out, for improve knowledge of chemical structures. Our compounds were introduced into the binding sites according to the published crystal structures. The global chemical reactivity descriptors for molecules have been computed (Table 1), like; S; softness (measures stability of molecules and chemical reactivity with direct proportional, $\eta$; hardness (reciprocal of softness), $\mu$; chemical potential, $\chi$; electronegativity strength catching electrons[33], the $\mu-$; electron donating power, $\mu+$; potency for catching electron, $\omega$-; electro donating capacity, $\omega+$; electro accepting capacity, $\omega^{ \pm}$; net electrophilicity (measuring a relative powers between electron accepting and electron donating) [15], wi; Electrophilicity index in ground state (determining decreasing energy obtained from maximal electrons current movement between donor and acceptor media), wi ${ }^{\mathrm{Vs}}$; Electrophilicity index in valance state. These parameters are represented in terms I; ionization potential and A; electron affinity[15], the previous terms represented in.

\subsubsection{Selection of proteins structures.}

Docking experiment was carried out for the target active site into a-glucosidase(PDB: 4yvx) and $\beta$-amylase(PDB: 4gqr) using MOE 2015[17]. The errors of active sites were corrected by the structure preparation process in MOE. After the correction, hydrogens were added and partial charges (Amber12:EHT) were calculated. Energy minimization (AMBER12:EHT, root mean square gradient: 0.100) was performed.

\subsubsection{Binding site analysis}

The binding site of each receptors were identified through the MOE Site Finder program, which uses a geometric approach to calculate putative binding sites in a protein, starting from its tridimensional structure. This method is not based on energy models, but only on alpha spheres, which are a generalization of convex hulls. The prediction of the binding sites, performed by the MOE Site Finder module, confirmed the binding sites defined by the co-crystallized ligands in the holo-forms of the investigated proteins.

\subsubsection{MOE Stepwise Docking Method:}

Page $10 / 22$ 
The crystal structures of the of enzymes were obtained. Water and inhibitors molecule were removed, and hydrogen atoms were added. The parameters and charges were assigned with MMFF94x force field. After alpha-site spheres were generated using the site finder module of MOE. The optimized 3D structures of molecules were subjected to generate different poses of ligands using triangular matcher placement method, which generating poses by aligning ligand triplets of atoms on triplets of alpha spheres represented in the receptor site points, a random triplet of alpha sphere center was used to determine the pose during each iteration. The pose generated was rescored using London dG. scoring function. The poses generated refined with MMFF94x forcefield, also, the solvation effects were treated. The Born solvation model (GB/VI) was used to calculate the final energy, and the finally assigned poses were assigned a score based on the free energy in $\mathrm{Kcal} / \mathrm{mol}$.

\subsubsection{ADMET predictions}

The ADMET in silico profile was applied using "MOE" and "admetSAR" tools to predication of pharmacokinetic and ADMET characters (absorption, distribution, metabolism, excretion, and toxicity).

\section{Conclusions}

The glucosinolates of both Carrichtera annua and Farsetia aegyptia (Crucifereae family) were identified. Some of the obtained Gls. were identified as it is and the others were enzymatically hydrolyzed to the corresponding isothiocyanates. The identified compounds are : 4methylthio-3-butenyl Gls. and 6-methyl sulfonylhexyl Gls. from CA while 6-methylsulfonyl-6-hydroxy hexyl ITC., 4-pentenyl Gls., 3-Methylthio propyl ITC.,5-hydroxy pentyl ITC. and 4-methylsulphinyl butyl ITC. from FA. the future experiments will be conducted to isolate the glucosinolates of Farsetia aegyptia in reasonable quantity to be able to identify them by different spectroscopic measurements and to investigate their activity as antitumor agents. The obtained Docking data showed that the ability interaction for Gls via. a-glucosidase and amylase. We predict that this Gls. may to be a suitable inhibitor, and these can be used as antidiabetic agent. The ADMET in silico showed that, these compounds have a good oral bioavailability and high ability transport through "BBB". Furthermore, when applied these compounds showed via the "rodent toxicity profile" no observed any marked carcinogenic and health effect.

\section{Abbreviations}

\begin{tabular}{|c|c|}
\hline E: The total energy (Kcal/mol). & I: Ionization potential, \\
\hline LUMO: Lowest Occupied Molecular Orbital (eV) & A; electron affinity; \\
\hline HOMO: Highest Occupied Molecular Orbital (eV) & n: Hardness(eV), \\
\hline $\begin{array}{l}\Delta G: \text { difference between HOMO and LUMO energy } \\
\text { levels }(\mathrm{eV})\end{array}$ & S: Softness(eV), \\
\hline$\Delta$ Nmax: maximum number of electrons transfer. & $\chi$ : Electronegativity (eV); \\
\hline $\begin{array}{l}\text { E_score1; Initial free binding energy of the ligand } \\
\text { from a given pose. }\end{array}$ & $\boldsymbol{\mu}+$ : electron accepting chemical potentials, \\
\hline $\begin{array}{l}\Delta E \text { : Final free binding energy of the ligand from } \\
\text { a given pose, }\end{array}$ & $\boldsymbol{\mu}$-: electron donating chemical potentials, \\
\hline $\begin{array}{l}\text { E_conf; Free binding energy of the ligand from a } \\
\text { given conformer }\end{array}$ & $\boldsymbol{\omega + :}$ electron accepting capacity, \\
\hline $\begin{array}{l}\text { E_place. Free binding energy of the ligand from a } \\
\text { receptor. }\end{array}$ & $\boldsymbol{\omega}$-: Electrodonating capacity; \\
\hline $\begin{array}{l}\text { E.Int.: Affinity binding energy of ligand with } \\
\text { receptor, }\end{array}$ & $\omega \pm:$ :Electrophilicity index in valance state $(\mathrm{eV})$; \\
\hline $\begin{array}{l}\text { H.B.: Hydrogen bonding energy between protein } \\
\text { and ligand. }\end{array}$ & Evdw: Van der Waals energies between the ligand and the receptor. \\
\hline Eele: Electrostatic interaction with the receptor, & $\begin{array}{l}\text { RMSD; The root mean square deviation of the pose of the docking pose compared to } \\
\text { the co-crystal ligand position. }\end{array}$ \\
\hline
\end{tabular}

\section{Declarations}

\section{Availability of data and materials}

All data generated or analyzed during this study are included in this published article.

\section{Acknowledgements}


Not applicable.

Funding

This research did not receive any specific grant from funding agencies in the public, commercial, or not-for-profit sectors.

Author information

- Department of chemistry, faculty of sciences and arts, Mukhwah, Albaha university, , Albaha, Saudi Arabia

Khaled A. Abdelshafeek, Ahmed A. Elhenawy, and AbdulAziz Ali Alomari

- Department chemistry of medicinal plants, Pharmaceutical Industries Div., National Research Centre,33 El Buhouth St.(Former El Tahrir St.), 12622-Dokki, Giza, Egypt.

Khaled A. Abdelshafeek, Walid E. Abdallah.

- Chemistry Department, Faculty of Science, Al-Azhar University (Boys Branch),Nasr City, Cairo, Egypt.

Ahmed A. Elhenawy

- Chemistry Department, Faculty of Science, Taif University, Saudi Arabia.

Abeer M. Alosaimi

- Chemistry Department, King Abdulaziz University, 80203 Jeddah, Saudi Arabia.

L.M.Al-Harbi

Contributions

K.A.A.: conceived and designed the experiments. W.E.A: performed the experiments and wrote the paper. A.A.E.: have performed evaluation and validation of docking methods and scoring functions and drafted the manuscript. A.A.E. and K.A.A.: analyzed and interpreted the data. K.A.A. and A.A.E.: outlined the research strategy and revised the manuscript. A.A.A. and L.M.A. has completed the literature search. All authors read and approved the final manuscript.

\section{Contributions}

Correspondence to Ahmed Elhenawy.

Ethics declarations

Ethics approval and consent to participate

Not applicable.

Consent for publication

Not applicable.

Competing interests

The authors declare that they have no competing interests.

Additional information

Publisher's Note Springer Nature remains neutral with regard to jurisdictional claims in published maps and institutional affiliations.

\section{References}

1. Rizk A. Phytochemistry of the Flora of Qatar. 1986

2. Boulos L. Flora of egypt: Al Hadara Publishing Cairo; 2005

Page $12 / 22$ 
3. Abdelshafeek KA, ElMissiry MM, Hussiny HA, Seif MM. The Flavonoids and Anticomplement Activity of two Cruciferous Plants Growing in Egypt

4. Bhandari SR, Jo JS, Lee JG (2015) Comparison of Glucosinolate Profiles in Different Tissues of Nine Brassica Crops. Molecules 20(9):15827-15841. doi:10.3390/molecules200915827. PubMed PMID: 26334264; PubMed Central PMCID: PMCPMC6331803. Epub 2015/09/04.

5. Bellostas N, Sørensen JC, Sørensen H, Agriculture (2007) Profiling glucosinolates in vegetative and reproductive tissues of four Brassica species of the U-triangle for their biofumigation potential. J Journal of the Science of Food 87(8):1586-1594

6. Clarke DBJAM. Glucosinolates, structures and analysis in food. 2010;2(4):310-25

7. Fahey JW, Zalcmann AT, Talalay PJP. The chemical diversity and distribution of glucosinolates and isothiocyanates among plants. 2001;56(1):5-51

8. Al-Gendy A, Lockwood GJF, journal f. GC-MS analysis of volatile hydrolysis products from glucosinolates in Farsetia aegyptia var. ovalis. 2003;18(2):148 - 52

9. Al-Gendy AA, Lockwood GB (2005) Production of glucosinolate hydrolysis products in Farsetia aegyptia suspension cultures following elicitation. Fitoterapia 76(3-4):288-295. doi:10.1016/j.fitote.2005.03.013. PubMed PMID: 15885925. Epub 2005/05/12.

10. Visentin M, Tava A, lori R, Palmieri SJJoa, chemistry f. Isolation and identification for trans-4-(methylthio)-3-butenyl glucosinolate from radish roots (Raphanus sativus L.). 1992;40(9):1687-91

11. Nair SS, Kavrekar V, Mishra AJEJoEB. In vitro studies on alpha amylase and alpha glucosidase inhibitory activities of selected plant extracts. 2013;3(1):128-32

12. Agarwal P, Gupta RJRRJMHS. Alpha-amylase inhibition can treat diabetes mellitus. 2016;5:1-8

13. Elhenawy AA, Al-Harbi L, El-Gazzar M, Khowdiary MM, Moustfa A (2019) Synthesis, molecular properties and comparative docking and QSAR of new 2-(7-hydroxy-2-oxo-2H-chromen-4-yl) acetic acid derivatives as possible anticancer agents. J Spectrochimica Acta Part A: Molecular Biomolecular Spectroscopy 218:248-262

14. Elgendy A, Nady H, El-Rabiei M, Elhenawy AAJRA. Understanding the adsorption performance of two glycine derivatives as novel and environmentally safe anti-corrosion agents for copper in chloride solutions: experimental, DFT, and MC studies. 2019;9(72):42120-31

15. Ali IO, Hanafy Al, Salama TM, El-Nasser KS, El-Henawy AA, Guma HA et al. Synthesis, structural configuration and DFT molecular orbital studies of [Mn-2 [benzo [b] oxazole] acetonitrile] complexes encapsulated in ZSM-5: Direct synthesis of phenol by benzene hydroxylation. 2018;262:35-48

16. El-Henawy AA, Basta AH, El-Saied H, Abdel-Shakour EH, Hasanin M, El-Sheikh HHJEJAC. Discovery potent of Bagasse (CMC-L-Phe) as bioactive material based on DFT calculations. 2018;13(5):1-16

17. Kitchen DB, Decornez H, Furr JR, Bajorath JJNrDd. Docking and scoring in virtual screening for drug discovery: methods and applications. 2004;3(11):935-49

18. Luque FJ, López JM, Orozco M (2000) Perspective on “Electrostatic interactions of a solute with a continuum. A direct utilization of ab initio molecular potentials for the prevision of solvent effects". Springer, Theoretical Chemistry Accounts, pp 343-345

19. Fukui K (1982) Role of frontier orbitals in chemical reactions. Science 218(4574):747-754. doi:10.1126/science.218.4574.747. PubMed PMID: 17771019. Epub 1982/11/19.

20. Wildman SA, Crippen GM (1999) Prediction of physicochemical parameters by atomic contributions. J Chem Inf Comput Sci 39(5):868873

21. Elhenawy AA, Al-Harbi L, Moustafa GO, El-Gazzar M, Abdel-Rahman RF, Salim AEJDD, Development et al. Synthesis, comparative docking, and pharmacological activity of naproxen amino acid derivatives as possible anti-inflammatory and analgesic agents. 2019;13:1773-90

22. Molecular Operating Environment (MOE) CCGU, 1010 handbook St. West, Suite 910, Montreal, QC, Canada, H3A 2R7, 2017

23. Corbeil CR, Williams Cl, Labute PJJoc-amd. Variability in docking success rates due to dataset preparation. 2012;26(6):775-86

24. Daina A, Michielin O, Zoete V (2017) SwissADME: a free web tool to evaluate pharmacokinetics, drug-likeness and medicinal chemistry friendliness of small molecules. Sci Rep 7:42717. doi:10.1038/srep42717. PubMed PMID: 28256516; PubMed Central PMCID: PMCPMC5335600. Epub 2017/03/04.

25. Yang H, Lou C, Sun L, Li J, Cai Y, Wang Z et al. admetSAR 2.0: web-service for prediction and optimization of chemical ADMET properties. 2018;35(6):1067-9

26. Ritchie TJ, Ertl P, Lewis R (2011) The graphical representation of ADME-related molecule properties for medicinal chemists. Drug Discov Today 16(1-2):65-72 doi: 10.1016/j.drudis.2010.11.002. PubMed PMID: 21074634

27. Zhao YH, Abraham MH, Le J, Hersey A, Luscombe CN, Beck G et al (2002) Rate-limited steps of human oral absorption and QSAR studies. Pharm Res 19(10):1446-1457. doi:10.1023/a:1020444330011. PubMed PMID: 12425461. Epub 2002/11/12.

Page $13 / 22$ 
28. Zhao Y, Zheng X, Zhang H, Zhai J, Zhang L, Li C et al (2015) In vitro inhibition of AKR1Cs by sulphonylureas and the structural basis. Chem Biol Interact 240:310-315. doi:10.1016/j.cbi.2015.09.006. PubMed PMID: 26362498. Epub 2015/09/13.

29. Banerjee P, Eckert AO, Schrey AK, Preissner R. ProTox-II: a webserver for the prediction of toxicity of chemicals. Nucleic Acids Res. 2018;46(W1):W257-W263. Epub 2018/05/03. doi:10.1093/nar/gky318. PubMed PMID: 29718510; PubMed Central PMCID: PMCPMC6031011

30. Cheng F, Li W, Zhou Y, Shen J, Wu Z, Liu G et al (2012) admetSAR: a comprehensive source and free tool for assessment of chemical ADMET properties. J Chem Inf Model 52(11):3099-3105. doi:10.1021/ci300367a. PubMed PMID: 23092397. Epub 2012/10/25.

31. Bento AP, Gaulton A, Hersey A, Bellis LJ, Chambers J, Davies M et al. The ChEMBL bioactivity database: an update. Nucleic Acids Res. 2014;42(Database issue):D1083-90. Epub 2013/11/12. doi: 10.1093/nar/gkt1031. PubMed PMID: 24214965; PubMed Central PMCID: PMCPMC3965067

32. Stewart JJ (2013) Optimization of parameters for semiempirical methods VI: more modifications to the NDDO approximations and reoptimization of parameters. J Mol Model 19(1):1-32. doi:10.1007/s00894-012-1667-x. PubMed PMID: 23187683; PubMed Central PMCID: PMCPMC3536963. Epub 2012/11/29.

33. Ali IO, Salama TM, Bakr MF, El-Henawy AA, Lateef MA, Guma HAJRoCl. Synthesis of nano-sized zeolite-Y functionalized with 5-amino-3thiomethyl 1H-pyrazole-4-carbonitrile for effective Fe (III)-chelating strategy. 2018;44(9):5193-222

\section{Figures}

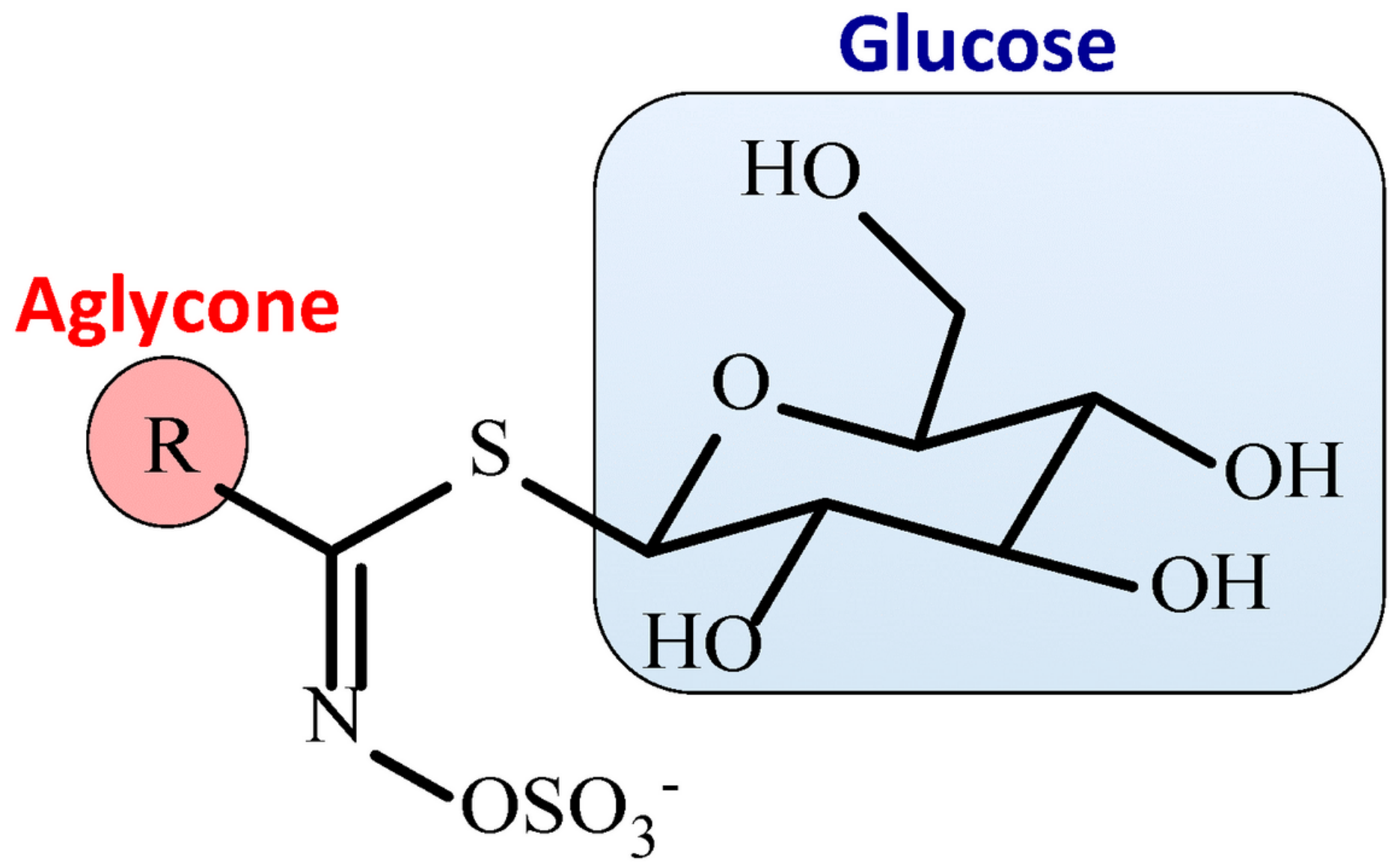

Figure 1

The chemical structure of glucosinolates 


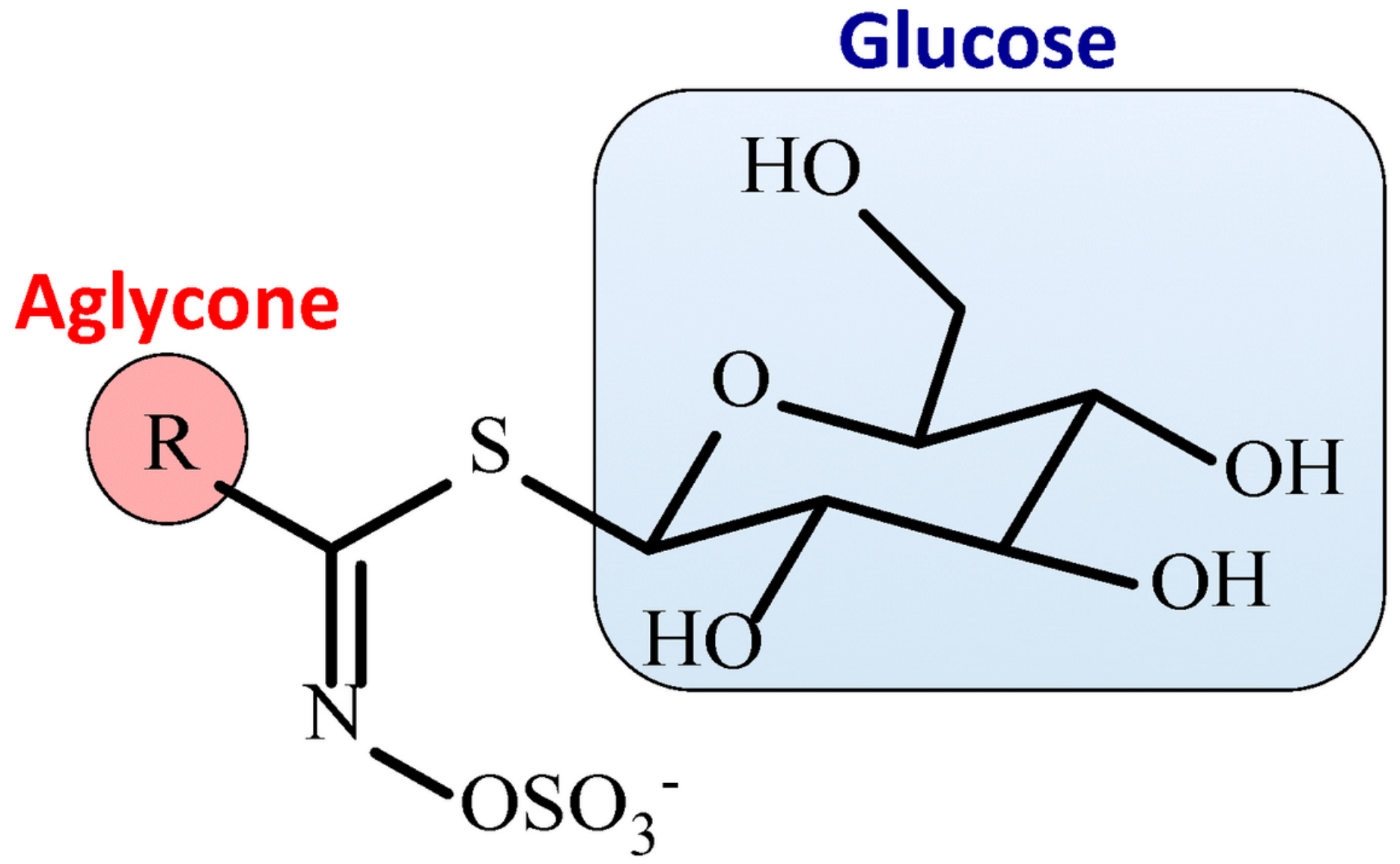

Figure 1

The chemical structure of glucosinolates

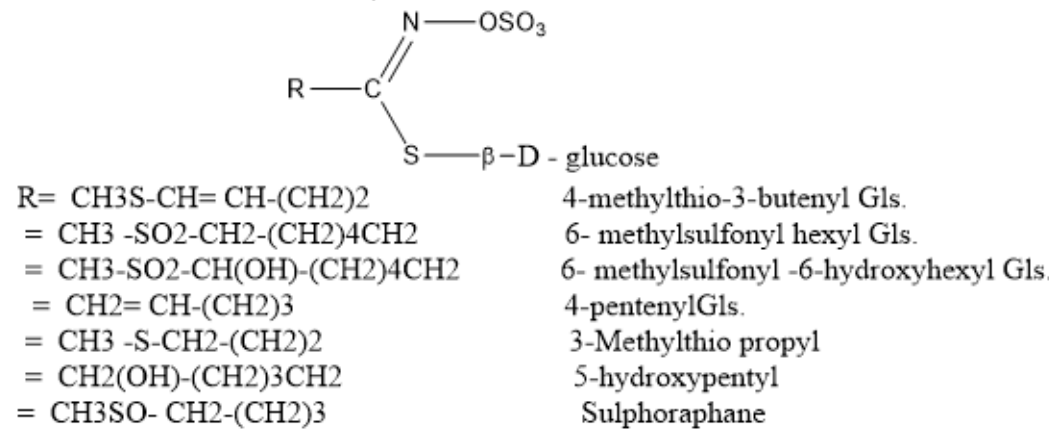

Figure 2

Identified isolated compounds

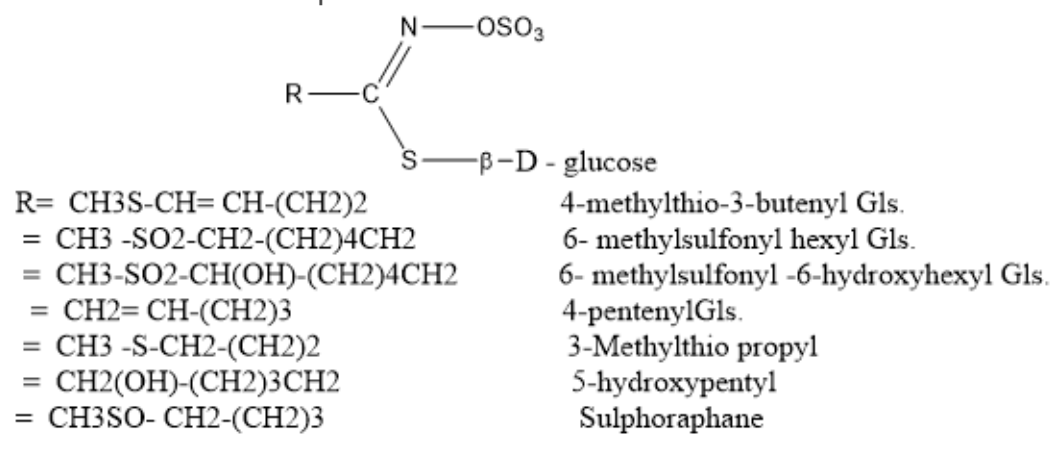

Figure 2 
Identified isolated compounds
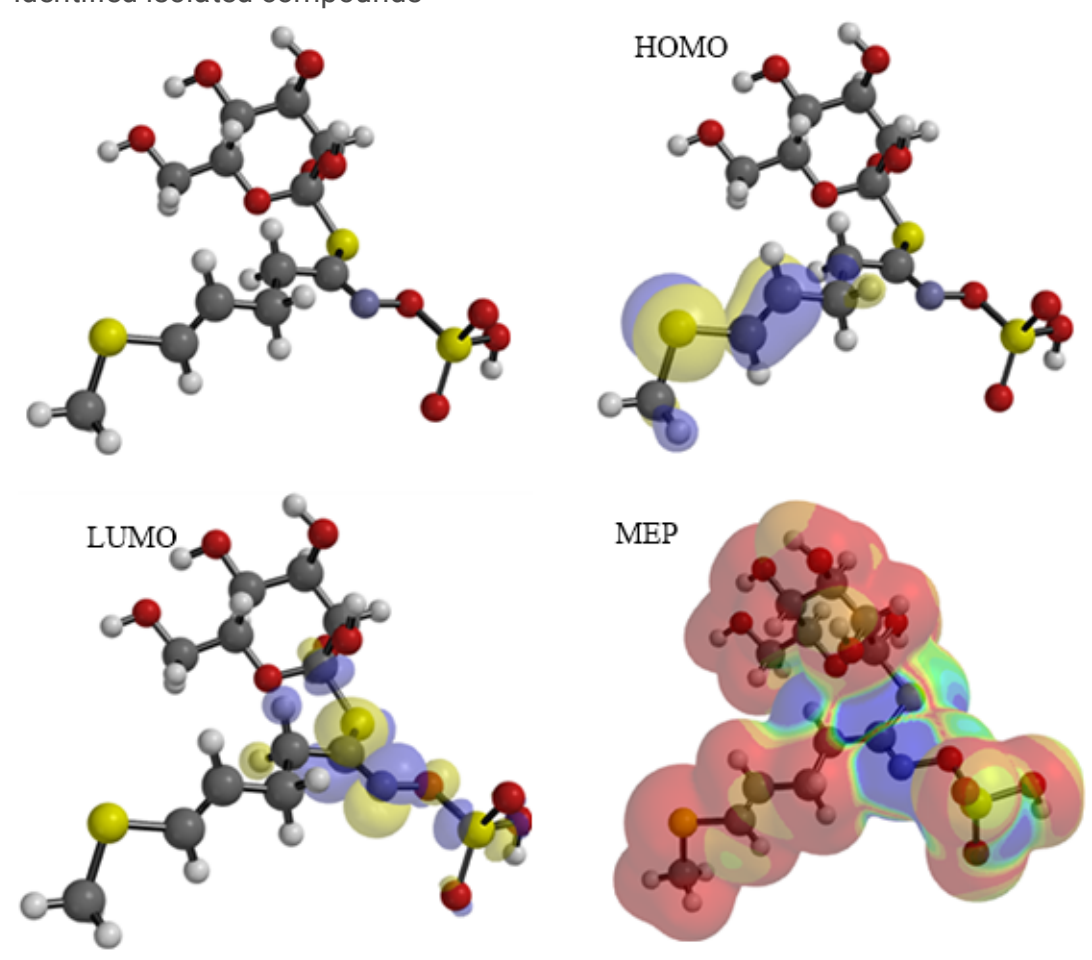

Figure 3

Plotting optimization geometry and molecular orbital for HOMO, LUMO and MEP of 4-methythio-3-butenyl glucosinolate.
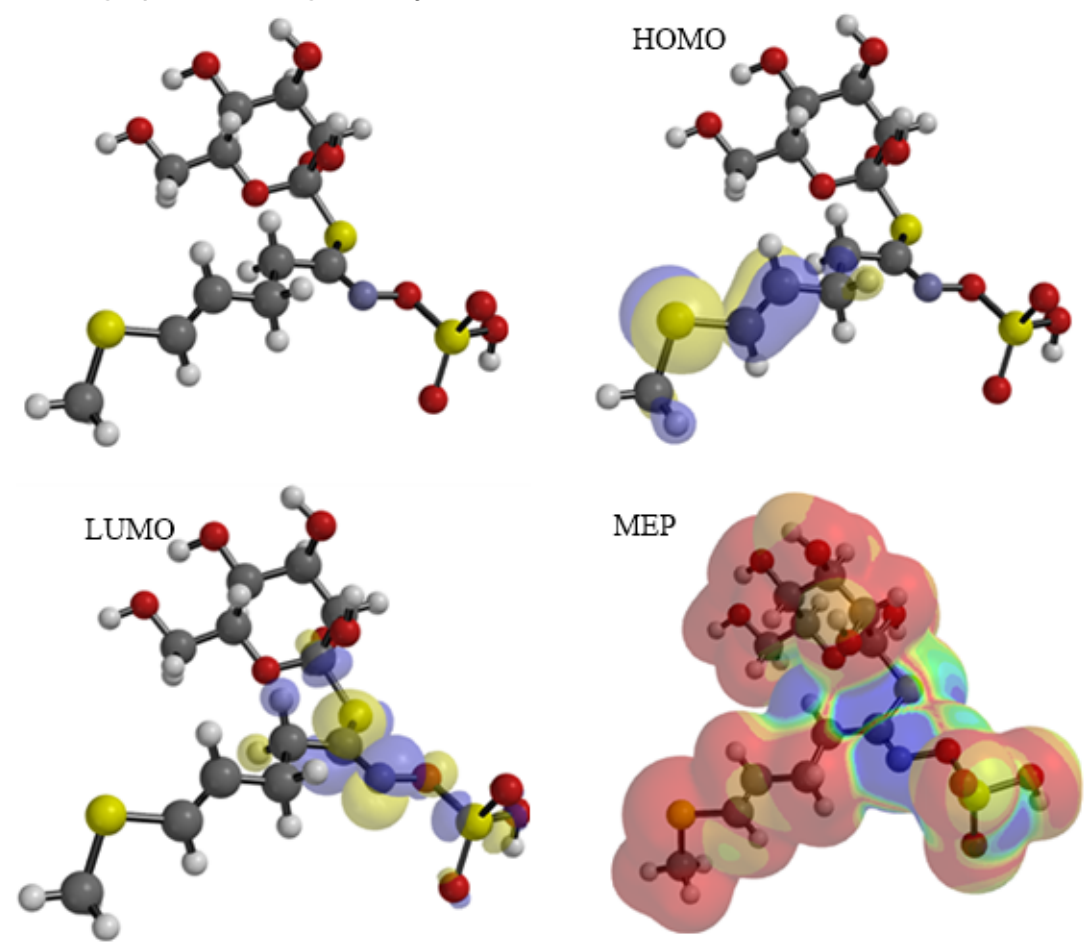

Figure 3

Plotting optimization geometry and molecular orbital for HOMO, LUMO and MEP of 4-methythio-3-butenyl glucosinolate. 


\section{A. Glimipride}
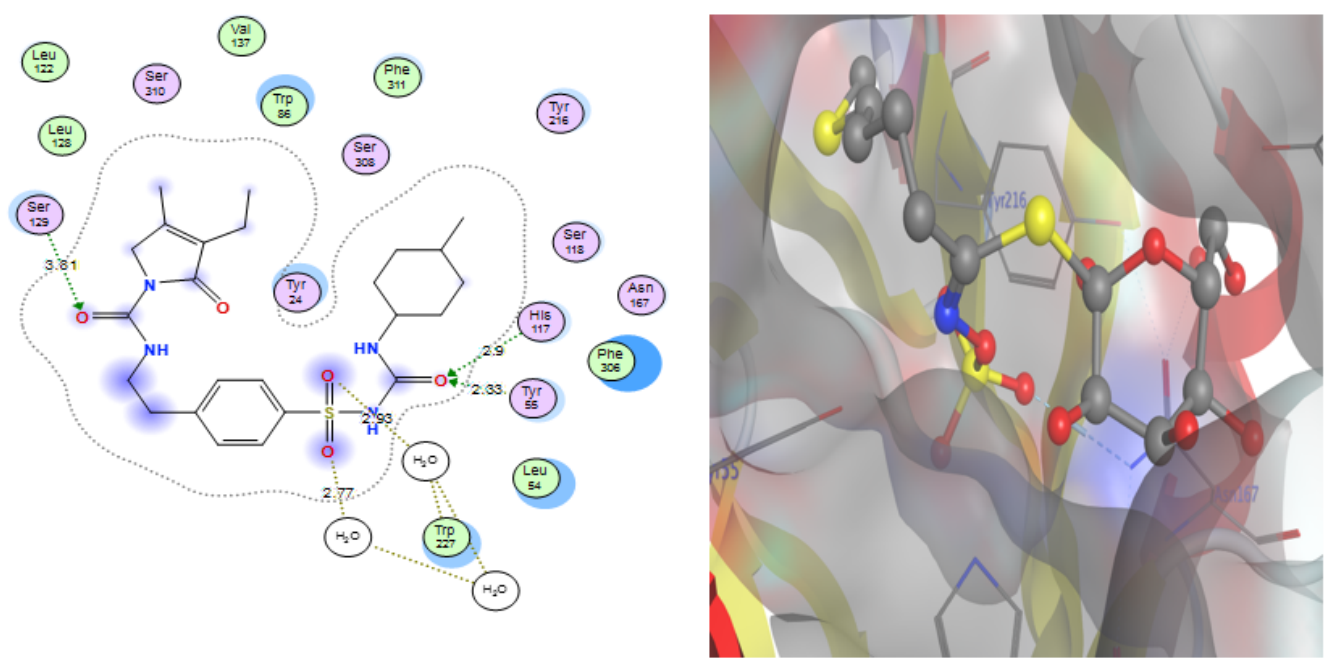

B. GLs.

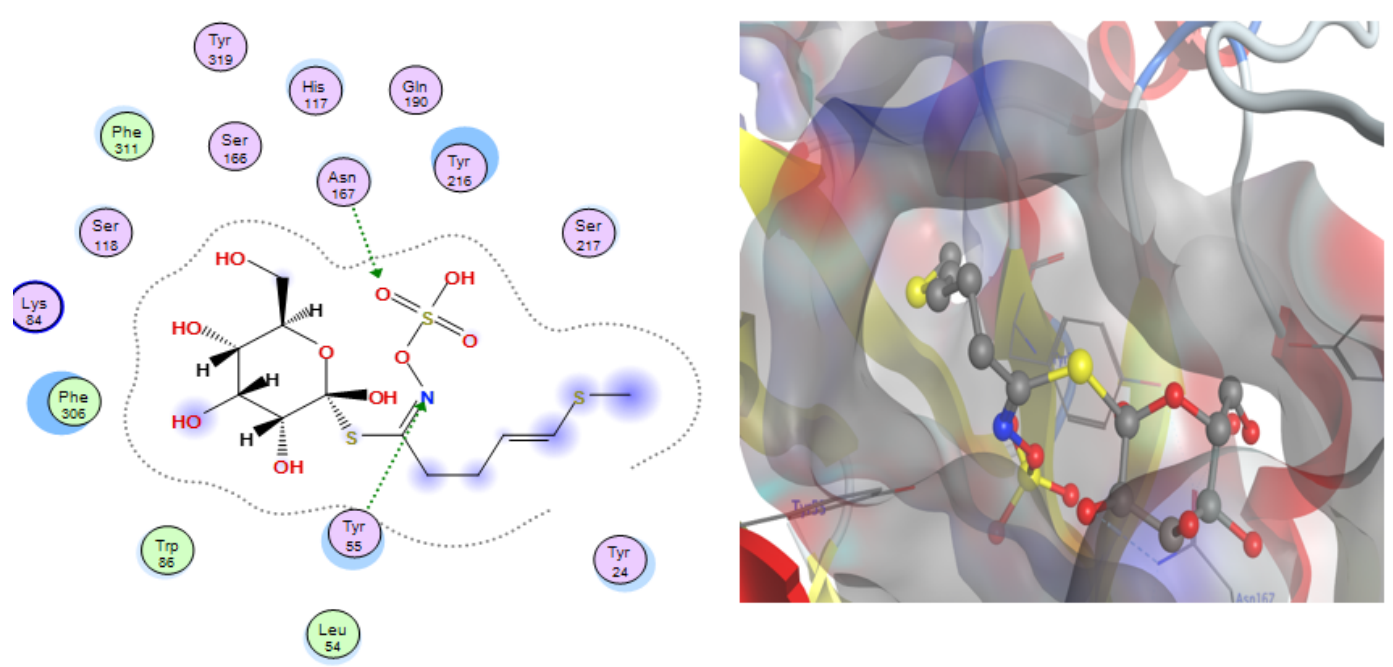

\section{Figure 4}

Interaction between A.) reference dug and B.) Gls. with binding site of a- glucosidase . 


\section{A. Glimipride}
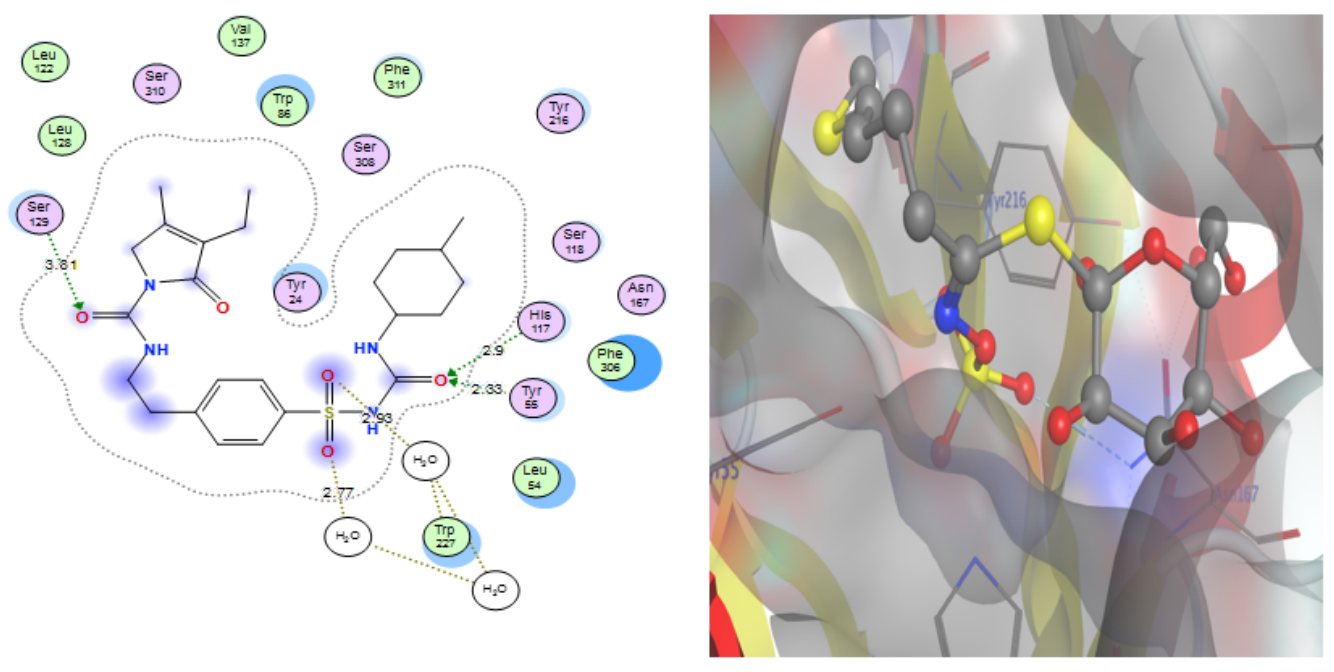

B. GLs.

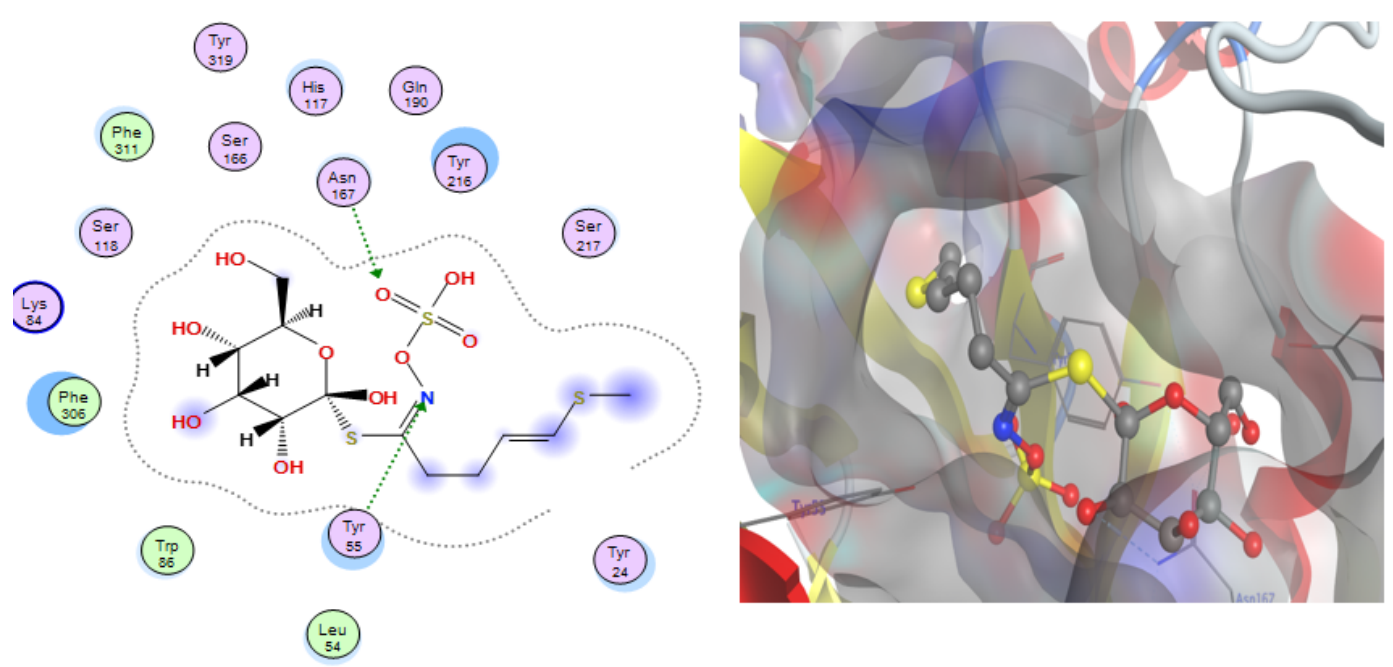

\section{Figure 4}

Interaction between A.) reference dug and B.) Gls. with binding site of a- glucosidase . 


\section{A. Reference drug}

(ii: (iii)

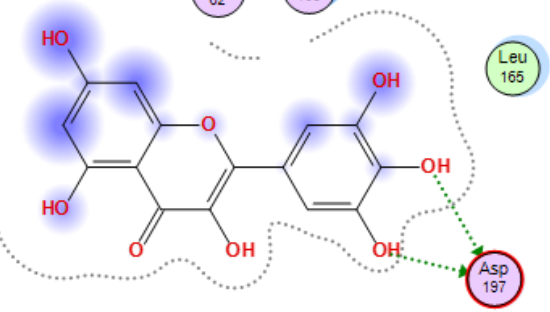

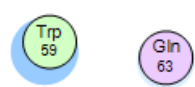

$\left(\begin{array}{l}\text { His } \\ 101\end{array}\right.$ (:i:)

(:i)
(Ala

(Giu

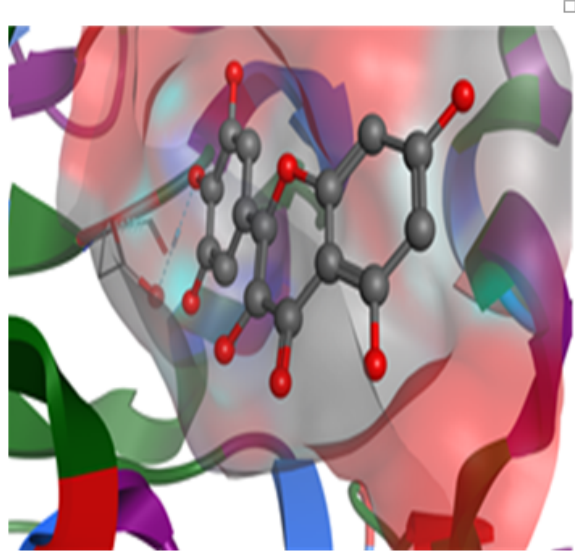

B. GLs.

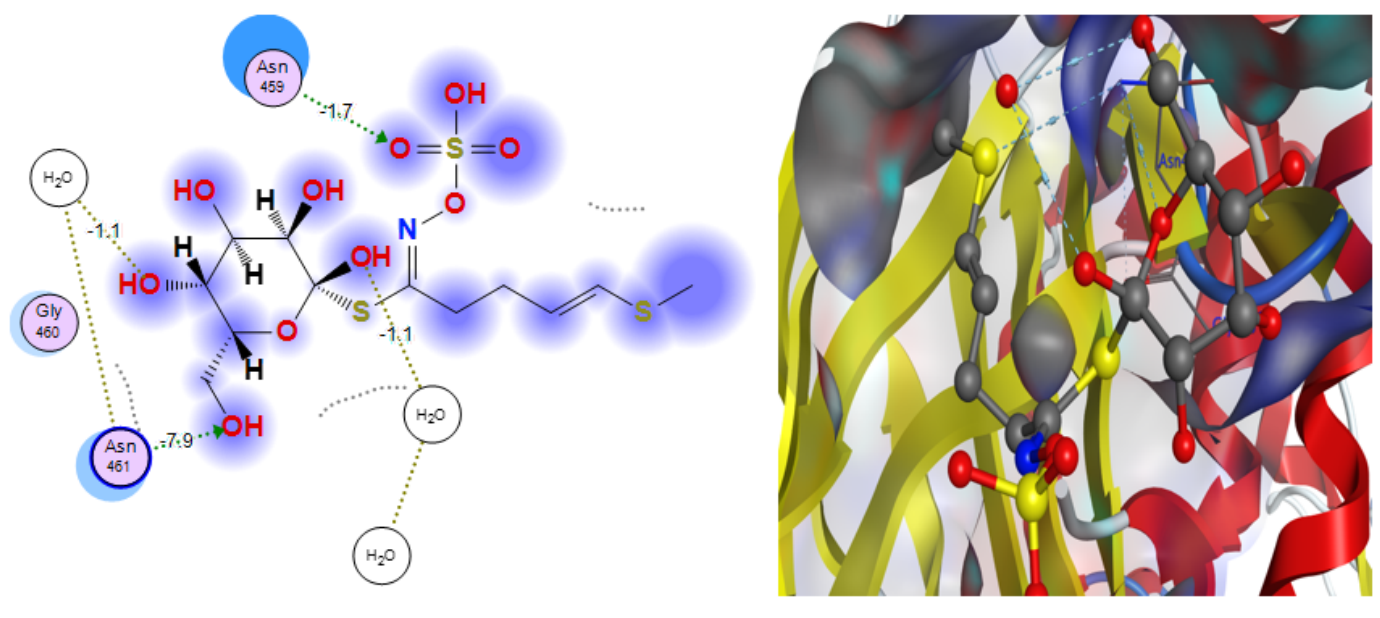

Figure 5

Interaction between A.) reference dug and B.) Gls. with binding site of a- amylase. 


\section{A. Reference drug}

(ii: (iii)

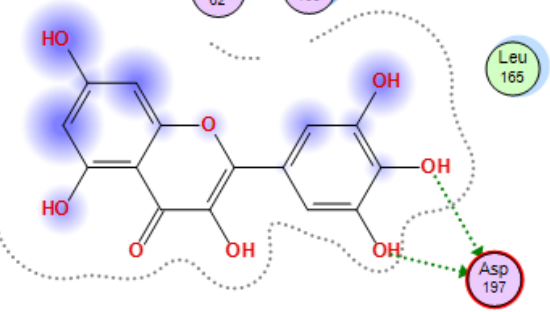

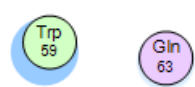

$\left(\begin{array}{l}\text { His } \\ 101\end{array}\right.$ (:i:)

(:i)
(Ala

(Giu

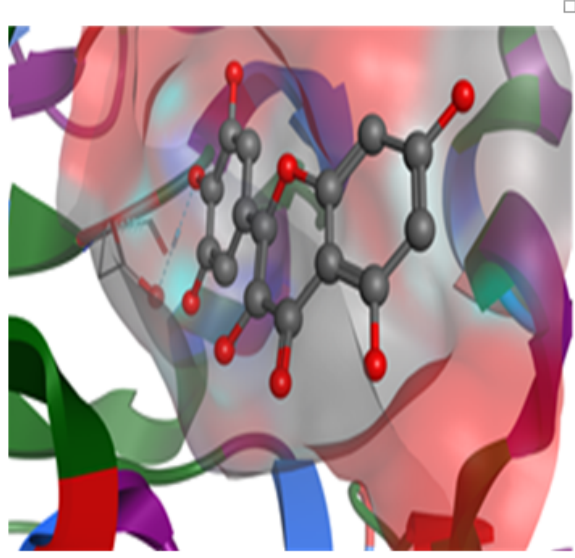

B. GLs.

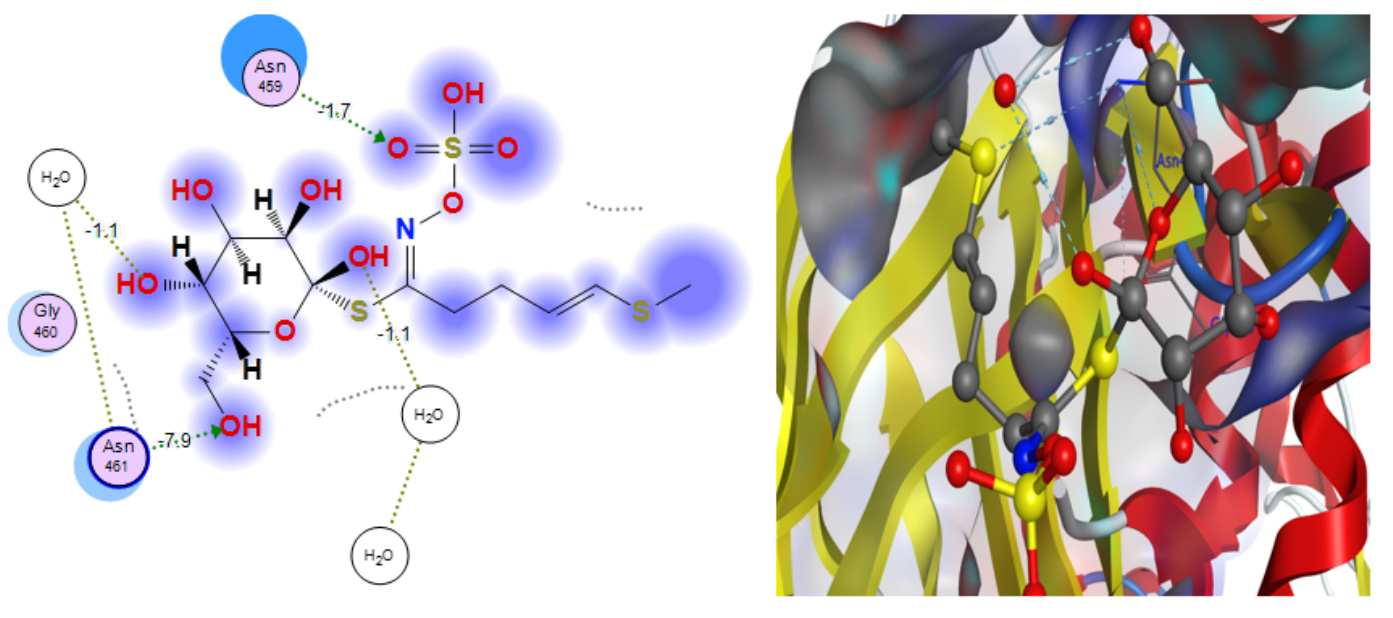

Figure 5

Interaction between A.) reference dug and B.) Gls. with binding site of a- amylase. 
A

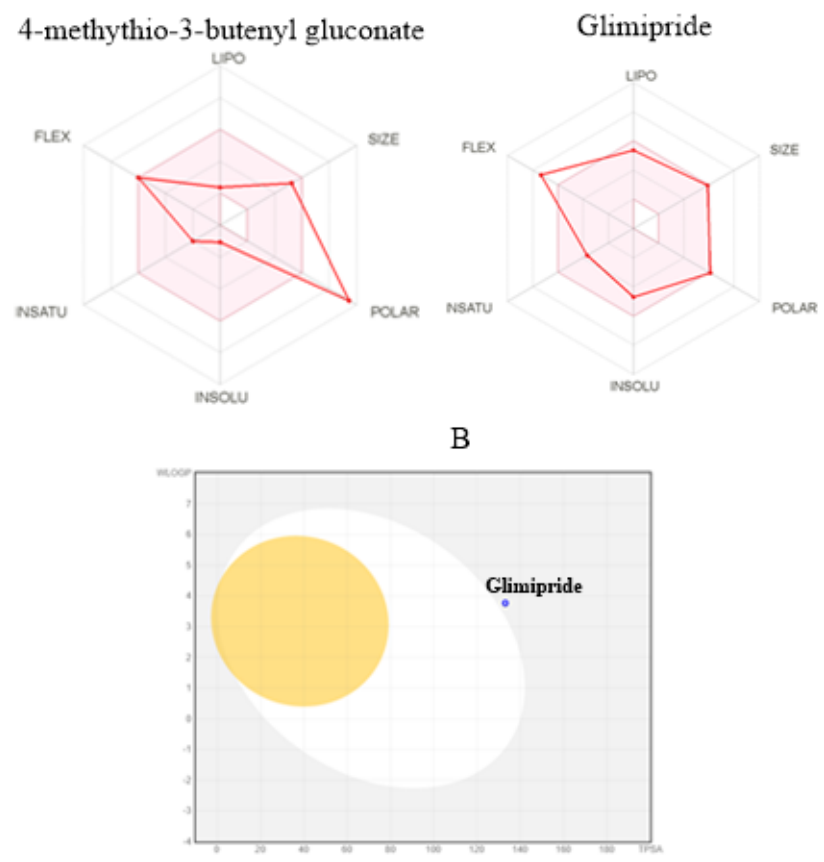

Figure 6

A; Bioavailability Radar plot of 4-methythio-3-butenyl glucosinolate. The pink area shows the optimal range for each properties (Lipophilicity: $-0.7 \leq \mathrm{XLOGP} 3 \leq+5.0$, size: $150 \leq \mathrm{MW} \leq 500 \mathrm{~g} / \mathrm{mol}$, polarity: TPSA $\leq 140 \AA 2$, solubility: log $\mathrm{S} \leq 6$, saturation: fraction of carbons in the hybridization sp3 $\geq 0.25$, and flexibility: rotatable bonds $\leq 9$. B; BOILED-Egg plot of the predicted compounds 4-methythio-3-butenyl glucosinolate and Glimipride. White region represented a highly probable HIA (GI) absorption, and the yellow region is for highly probable BBB permeation. The outside grey region stands for molecules are predicted with low absorption and not brain penetration. As well, the point in blue color represented as P-gp substrate (PGP+) and in red as P-gp non-substrate (PGP-).

A

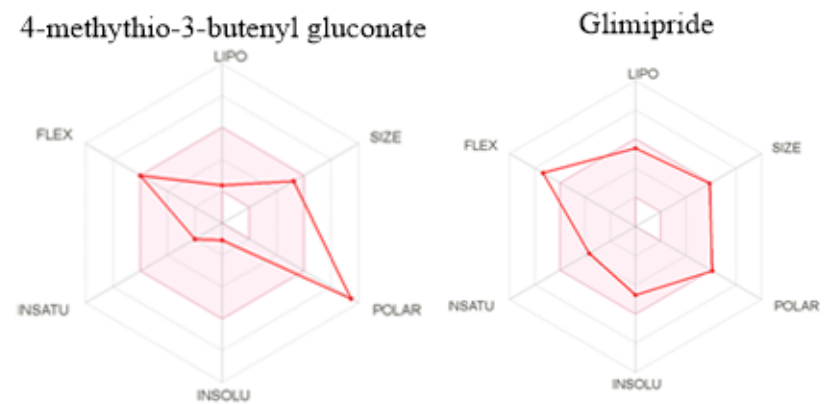

B

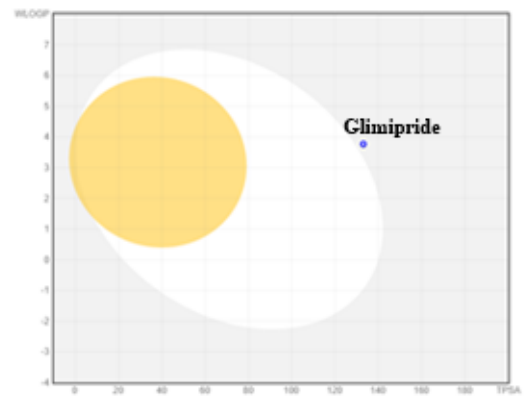

Figure 6

A; Bioavailability Radar plot of 4-methythio-3-butenyl glucosinolate. The pink area shows the optimal range for each properties (Lipophilicity: $-0.7 \leq \mathrm{XLOGP} 3 \leq+5.0$, size: $150 \leq \mathrm{MW} \leq 500 \mathrm{~g} / \mathrm{mol}$, polarity: TPSA $\leq 140 \AA 2$, solubility: log $\mathrm{S} \leq 6$, saturation: fraction of carbons in the hybridization sp3 $\geq 0.25$, and flexibility: rotatable bonds $\leq 9$. B; BOILED-Egg plot of the predicted compounds 4-methythio-3-butenyl glucosinolate and Glimipride. White region represented a highly probable HIA (GI) absorption, and the yellow region is for highly probable BBB 
permeation. The outside grey region stands for molecules are predicted with low absorption and not brain penetration. As well, the point in blue color represented as P-gp substrate (PGP+) and in red as P-gp non-substrate (PGP-). 